\title{
La epidemia de cólera de 1833 y la mortalidad en la Ciudad de México
}

\author{
María del Pilar Velasco M.L.*
}

En un nuevo intento por conocer el comportamiento de ios hechos vitales durante el sigio XIX, en este trabajo se analiza la mortalidad ocasionada por cólera morbus en la Ciudad de México durante 1833, en el entendido de que, aunque no fue la única epidemia de esta naturaleza, por ser la primera y debido a su gran propagación, dejó sentir su impacto en todos los ámbitos de la vida social, económica y política de la metrópoli.

A partir de los datos estimados por numerosos autores en cuanto al volumen total de población y con base en diversos métodos estadísticos̀ y demográficos, se calculó la población probable de la Ciudad de México en 1833 y su correspondiente distribución por sexo y edad.

Los archivos parroquiales fueron la base para la estimación de los niveles de mortalidad; a partir de estos datos se calcularon tablas de vida abreviadas por sexo para 1832 y 1833 , y en un esfuerzo por analizar el peso específico del cólera en la mortalidad general se construyeron tablas adicionales por causa de muerte.

Desde el punto de vista estrictamente demográfico, se observa que casi 5\% de la población total de la Ciudad de México murió a causa del cólera; que los 1200 hombres y mujeres de menores de cuatro años que fallecieron a consecuencia de la epidemia dejaron generaciones incompletas a largo plazo, que la desaparición de casi 2700 individuos entre $15 \mathrm{y}$ 44 años afectó a hombres y mujeres en edad reproductiva, que al suprimir las defunciones ocasionadas por cólera, la esperanza de vida al nacimiento experimenta ganancias de 12.3 años entre los hombres y de 13.95 años entre las mujeres, etcétera.

Desde otro punto de vista, se hace notar el hecho de que las medidas sanitarias instrumentadas durante la epidemia trajeron consigo cambios importantes en la organización social, económica y urbana de la ciudad y que, a partir de entonces, se hizo aún más evidente la diferenciación social ante la muerte. Salud.

* Directora del Instituto Veracruzano de Investigaciones en Educación y 


\section{Introducción}

Desde hace varios años los especialistas en población han intentado ampliar el objeto de su atención y rebasar la perspectiva demográfica en sus aspectos meramente formales (es decir, el enfoque que estudia la dinámica numérica de las poblaciones, sus composiciones cualitativas y la interrelación de ambos), y han tratado de entenderla como una realidad histórica concreta, en la que el hombre mismo juega una parte importante.

En efecto, el estudio de las poblaciones ha sido replanteado y, en un intento por descubrir las vinculaciones entre las esferas fundamentales de la sociedad, se ha dado mayor importancia a los trabajos historicodemográficos, que posibilitan un mayor conocimiento de las características constantes o líneas generales del comportamiento de la población, a los que proporcionan una explicación más completa de las interrelaciones entre los fenómenos demográficos y las relaciones de producción, y a los que pretenden dar una explicación más acabada que, eventualmente, permita prever numerosas necesidades económicas y sociales.

Sin embargo, y a pesar del esfuerzo realizado en años recientes, en nuestro país siguen siendo escasas las investigaciones historicodemográficas y muchas de ellas son el resultado de la labor de otros especialistas (principalmente historiadores), que han intentado analizar el comportamiento de los hechos vitales desde la perspectiva de su particular disciplina.

Los demógrafos mexicanos siguen destinando la mayor parte de su esfuerzo al análisis de los procesos poblacionales actuales y a la elaboración de proyecciones, en parte debido a la importancia que se les atribuye, pero también como resultado de las dificultades inherentes a la realización de estudios históricos en este campo: la naturaleza de las fuentes de información, la generación de información específica, la necesidad de evaluar y ajustar los datos con técnicas particulares y, en fin, lo laborioso y prolongado de la tarea, es lo que la vuelve difícilmente financiable.

El presente documento forma parte de un trabajo más amplio (Velasco, 1984) en el que hemos tratado de vincular diversos aspectos sociales, económicos y políticos con los procesos demográficos, a través del análisis de la salud y de las condiciones socioeconómicas de la época.

La fuente de información más importante de este trabajo fue la constituida por los registros parroquiales, de los que se obtuvieron las actas de defunción individuales de aproximadamente 16000 decesos ocurridos entre 1832 y 1833 . Sin embargo, se recurrió a otras numerosas fuentes que hicieran posible realizar esti- 
maciones de la población de la época y analizar las condiciones sociales y económicas prevalecientes.

El documento consta de cinco partes fundamentales. En la primera, se encuentra un breve resumen sobre lo que el cólera morbus significaba para los médicos de la época y para la población en general.

La segunda sección se destina a la presentación y análisis de algunos datos sobre la población de la Ciudad de México en el siglo XIX, a la estimación de un volumen total y de una estructura por edad y sexo específica para el año 1833, que sirvieran de base para la estimación de los niveles de mortalidad.

En la tercera parte abordamos lo relativo a la mortalidad general: se revisan algunos datos elaborados por diversos autores, se hacen cálculos particulares para 1832 y 1833, y se presentan las tablas de vida abreviadas para cada sexo y para cada uno de los años considerados.

La mortalidad por cólera en 1833 se analiza en la cuarta parte del documento. En ésta hemos incluido lo relativo a las probabilidades de muerte, las esperanzas de vida y los sobrevivientes, y elaboramos nuevas tablas de vida abreviadas por sexo para 1833, esta vez por causa (por cólera y por causa diferente a ésta). Este ejercicio permitió tener una aproximación a la importancia que la epidemia de cólera tuvo sobre el nivel de la mortalidad general.

La quinta y última parte se dedica al análisis de los principales resultados y al establecimiento de algunas consideraciones finales sobre las consecuencias sociales y económicas que trajo consigo la epidemia de cólera de 1833 en la Ciudad de México.

Finalmente, introdujimos un anexo en el que hemos incluido algunos cuadros y gráficas que resultaron fundamentales en la elaboración de este trabajo y que pueden ser importantes para quien desee profundizar en el tema. Asimismo, se presenta la lista detallada de las causas de defunción que se encontraron en los registros parroquiales de 1832 y 1833, y que agrupamos (un poco arbitrariamente) bajo cinco grandes grupos.

\section{Consideraciones sobre el cólera morbus en el siglo XIX}

El cólera es una infección aguda del tracto intestinal; es una enfermedad microbiana, transmisible, endemoepidémica, que solamente afecta al hombre. Antiguamente era causada únicamente por el vibrión de koch, pero en la actualidad se encuentra cada vez más como origen de ella el vibrión El Tor.

Se caracteriza por una grave diarrea y vómitos, que conducen 
a la deshidratación y a la pérdida de electrólitos. "La iniciación súbita de los síntomas, su gravedad, la alta mortalidad y la ausencia de un tratamiento eficaz, hacen de ella una de las enfermedades más dramáticas de la historia de la humanidad." (Passmore y Robson, 1975:266.)

En la actualidad, sabemos que después de un periodo de incubación de dos a cuatro días, la enfermedad empieza bruscamente con vómitos, cólicos intestinales y diarrea y que, en ausencia de un tratamiento adecuado, la muerte sobreviene por colapso en $50 \%$ de los casos (la curación puede producirse espontá neamente, disminuyendo las pérdidas gastrointestinales, desapareciendo el colapso y mejorando el estado general).

También sabemos que el cólera se reconoce fácilmente hoy en día (sobre todo en etapas de epidemia) y que los vibriones pueden identificarse en las heces, pero que la importancia del diagnóstico precoz es fundamental para la puesta en marcha de la reanimación hidrolítica (Aceves, 1975:vol. VI).

En cuanto al tratamiento, se sabe que las mejores medidas consisten en el aislamiento de los enfermos en habitaciones cuyas paredes y suelos puedan ser desinfectados; en la reposición de líquidos y electrólitos y en la correción de la acidosis. Los medicamentos más eficaces para reducir el periodo de diarrea y la excreción de vibriones son la tetraciclina y la furazolidina, pero la eficacia de cualquiera de estas medidas estriba en la detección oportuna del mal y la inmediata instrumentación del tratamiento.

Durante el siglo XIX, sin embargo, era muy poco lo que se sabía al respecto y muy grande el temor que producía entre los médicos y la población en general. Sus síntomas fueron observados minuciosamente, de manera que surgieron diversas clasificaciones de las fases por las que atraviesa la enfermedad. Domínguez, por ejemplo, distinguía tres formas particulares de cólera morbus, en función de la cantidad y severidad de la diarrea (benigna, grave y fulminante) (Domínguez, 1889:170); Lozano, por su parte, clasificó las etapas de la enfermedad bajo cuatro rubros en los que consideraba, además de la diarrea, la presencia o ausencia de vómitos y otros cambios fisiológicos tales como las "modificaciones notables de la sangre y de la circulación", la cianosis, el estupor, la postración, la debilidad general, etcétera (Lozano, 1892).

A finales del siglo pasado el diagnóstico se realizaba por medio de un examen bacterioscópico de la secreción intestinal, pero no hay evidencia de que este tipo de estudios fueran llevados a cabo antes de 1880. Sin embargo, sí existían algunas teorías en torno a la etiología del cólera y se reconocía que uno de los principales medios de contagio era el agua, pero se afirmaba que era necesario 
que existiera, además, una propensión o receptividad especial por parte del individuo, para que el microorganismo evolucionara.

No existía un medicamento específico para el tratamiento del cólera, pero sí se conocían algunas medidas terapéuticas. Se sabía, por ejemplo, que lo primero era parar la evacuación intestinal "antes de que afectara gravemente la sangre y la circulación", y para lograrlo, a criterio del médico, se empleaba opio (generalmente láudano), calomelano, tanino, ácido carbónico, clorhidrato de cocaína, mercurio metálico, éter sulfúrico, etcétera.

La medicación era propiamente sintomática, de dudosa efectividad, y dado que el germen se alojaba en el intestino, se pensaba que ni las inyecciones ni los medicamentos ingeridos podían ser de gran utilidad, puesto que "son absorbidos, entrando inmediatamente en la sangre, donde no encontrándose la causa, no pueden ejercer alguna acción directa sobre el veneno colerígeno" (Domínguez, 1889:186).

Las medidas profilácticas más comunes consistían en hervir el agua, ingerir los alimentos muy cocidos, tostar el pan, hervir los utensilios de cocina y de mesa, hervir el agua destinada para el baño, así como para lavarse la cara y las manos varias veces al día, cubrir la boca y la nariz en caso de manipular cadáveres de coléricos, entre otras. Se hacía hincapié en el aseo, tanto personal como colectivo, y se recomendaba la desinfección de la habitación (y la casa misma) ocupada por el colérico.

También se consideraba necesario que el gobierno tomara parte en la tarea de prevenir la enfermedad a través de medidas tales como el cegar los pantanos, limpiar las acequias y las calles, quitar o destruir los muladares y demás focos de infección, vigilar e inspeccionar los mercados, las carnes, las bebidas, las harinas $\mathrm{y}$, en fin, todos los comestibles, pero a pesar de todas las acciones llevadas a cabo al respecto, las epidemias se esparcían por toda la ciudad.

A pesar de los grandes avances de la ciencia médica, durante el siglo XIX aún eran incipientes los conocimientos en torno a muchas de las enfermedades dominantes, incluyendo el cólera. Se había avanzado en lo que se refiere a la etiología, y sobre todo en cuanto a la observación y la clasificación de los síntomas, al diagnóstico y al pronóstico, pero los tratamientos no resultaban eficaces y se dirigían, en su mayor parte, hacia el alivio de los síntomas, sin atacar directamente la causa del padecimiento.

Es fácil imaginar el terror que producía una epidemia de cólera (o de cualquier otra enfermedad), que mermaba a la población en tan grandes proporciones y "cuyos efectos devastadores eran experimentados por varias generaciones". En la mayoría de los 
casos los medios de defensa no eran efectivos y toda clase de gente -hombres, mujeres, jóvenes, ancianos, ricos y pobres-sufrió las consecuencias.

En el caso de la Ciudad de México, la población más afectada por las epidemias fue sin duda la indígena, puesto que los barrios en los que habitaba eran los que se encontraban en peores condiciones, con mayores carencias sociales y con índices de hacinamiento más elevados que los de la población blanca (ubicada en los barrios centrales).

La Ciudad de México era considerada como propensa a la propagación de las epidemias, por sus particulares características naturales, pero era también reconocido el hecho de que uno de sus mayores problemas estribaba en las pésimas condiciones sociales, en la carencia de infraestructura y en el bajo nivel de vida de sus habitantes. Por ello, en 1870, García Cubas escribía:

... es preciso apuntar las verdaderas causas de la insalubridad en México, para no atribuirla como muchos pretenden, a su propia naturaleza; mi opinión a este respecto es diametralmente opuesta, porque, en efecto, ¿qué medidas se han tomado alguna vez para mejorar las condiciones higiénicas de la ciudad? ¿no vemos diariamente remover el cieno de inmundas atarjeas, impregnando el aire de miasmas nocivos? ¿se han dictado providencias para la conveniente inhumación de los cadáveres...?

... En los panteones en lugar de la fragancia de las flores, solamente se respiran, y muy particularmente en Santa Paula, miasmas deletéreos, que son tan desagradables al olfato como nocivos y peligrosos para la vida: la pésima costumbre de la inhumación en nichos, la situación de los panteones en los lugares en que reinan los aires y la de los hospitales en el centro de la población; los inmundos muladares que la rodean, y las demás circunstancias indicadas son causas suficientes para hacer insalubre el lugar más favorecido por la naturaleza... (García Cubas, 1870.)

En ese mismo año, propuso una serie de medidas tendientes a mejorar las condiciones de salubridad de la capital de la República, entre ellas destacan: la instrumentación de un sistema de desagüe directo y de canalización para todo el valle de México, el mejoramiento de las condiciones de vida de las clases menesterosas (tanto en sus "habitaciones húmedas y malsanas" como en sus hábitos alimentarios), el cegar las acequias y desecar los pantanos que rodeaban la ciudad, la destrucción de "los inmundos muladares que existen en los suburbios y sustituirlos por arboledas", el desplazamiento de los hospitales (ubicados en el centro de la ciudad) hacia las afueras, el perfeccionamiento del sistema de limpie- 
za de las atarjeas, el aprovisionamiento de agua a los barrios que carecían de ella, la construcción de inodoros en las casas en las que aún había atarjeas, el plantar árboles, el sustituir las cañerías de plomo por otras de fierro.

Sin embargo, a pesar de que muchas de estas ideas fueron puestas en práctica, las epidemias de cólera de 1833 y 1850 se propagaron rápidamente por toda la ciudad, causando una gran alarma por su letalidad. Y lo mismo ocurrió en 1882 en Chiapas, Tabasco y Oaxaca, cuando nuevamente la población se vio afectada por el flagelo de una nueva epidemia de cólera.

\section{La población de la Ciudad de México en el siglo XIX}

A pesar del interés que esta etapa de la historia de la Ciudad de México ha despertado y de los numerosos estudios existentes sobre su desarrollo, el problema del comportamiento demográfico ha sido mencionado sólo de manera tangencial y, en muchos casos, superficialmente. El uso de los documentos históricos ha sido limitado y casi exclusivo de los historiadores, debido en parte a la dificultad de acceso a los mismos, a la cantidad de tiempo que hay que invertir para seleccionar la información básica y a la carencia de una instrucción especializada que facilite la sistematización, la interpretación y el análisis del material.

Estimar el comportamiento de la mortalidad durante este periodo y valorar el impacto que la epidemia de cólera de 1833 tuvo sobre esta variable, obliga a considerar numerosas fuentes y métodos alternativos: dado que el registro nacional de estadísticas vitales empezó su operación regular e ininterrumpidamente después de 1867 (y sólo fue razonablemente uniforme a finales de la década de 1920) (Cook y Borah, 1980), y puesto que los levantamientos censales regulares se iniciaron propiamente en este siglo (aunque existen antecedentes importantes en 1790 y 1895), se hace necesario recurrir a estimaciones de población de diversos autores y a datos contenidos en los archivos parroquiales (la organización eclesiástica fue la encargada del registro de los asuntos de carácter civil durante el periodo).

Los montos de población estimados están en función de las consideraciones y los supuestos que los autores hacen sobre el número de habitantes, pero también dependen del método empleado para el análisis. Por eso encontramos que existen estimaciones diferentes para un mismo año. Así, por ejemplo, el Censo de Revillagigedo (Secretaría de Programación y Presupuesto, 1977) indica que para 1790 habitaban en la Ciudad de México 112926 perso- 
nas; la cifra se eleva a 129000 según Humboldt (1970) y a 128218 de acuerdo con Florescano, autores que basaron sus esti maciones en el mismo censo, pero que agregaron al volumen total el resultado de sus propios cálculos de subestimación. ${ }^{1}$

Cabe mencionar que durante la primera mitad del siglo XIX el crecimiento poblacional de este centro urbano fue lento, llegando incluso a ser negativo en varios periodos. Puesto que predominaban todavía muchas de las ideas que señalan que la riqueza de una nación está constituida por las tierras y por los hombres capaces de hacerlas producir, la ausencia de mecanismos de control de la fecundidad obliga a considerar que este débil crecimiento obedeció, fundamentalmente, a las altas tasas de mortalidad observadas en el periodo. ${ }^{2}$

Los nacimientos no siempre fueron suficientes para reponer las pérdidas ocasionadas por el elevado número de defunciones, y en la gráfica correspondiente podemos observar alzas o "picos" importantes en el número de decesos, en algunos años caracterizados por epidemias y guerras importantes. Resaltan en particular los siguientes:

1810 y siguientes Levantamiento armado por la Independencia.

1813 "Misteriosas fiebres del año trece", ocasionadas por el paludismo. El tifo, la tifoidea y las disenterías se vieron exacerbadas por la aglomeración, el hambre y la falta de vivienda.

1813-1814 La viruela iniciada en Veracruz llega a México.

1825

Epidemia de sarampión.

1833

Epidemia de cólera morbus iniciada en Tampico, que llegó en agosto a la Ciudad de México.

$1838 \quad$ Epidemia de tifo.

$1850 \quad$ Nueva epidemia de cólera morbus.

1853-1855 Continúan los brotes de cólera.

Muchas fueron las enfermedades y calamidades que asolaron al país provocando innumerables víctimas, pero el análisis de la situación epidemiológica es forzosamente limitado, ya que se carece de información suficiente acerca de los diversos factores biológicos, sociales, médicos, económicos, ecológicos y políticos que afectaron la salud y produjeron (o favorecieron) muchas de las enfermedades. Sin embargo, sabemos que hubo constantes catásderada.

${ }^{1}$ Florescano agrega, además, a la población militaræque no había sido consi-

${ }^{2}$ Algunos datos que apoyan esta hipótesis pueden ser encontrados en Pilar Velasco M.L., 1987. 
GRÁFICA 1

Nacimientos y Defunciones registrados en la Ciudad de México, 1810-1860

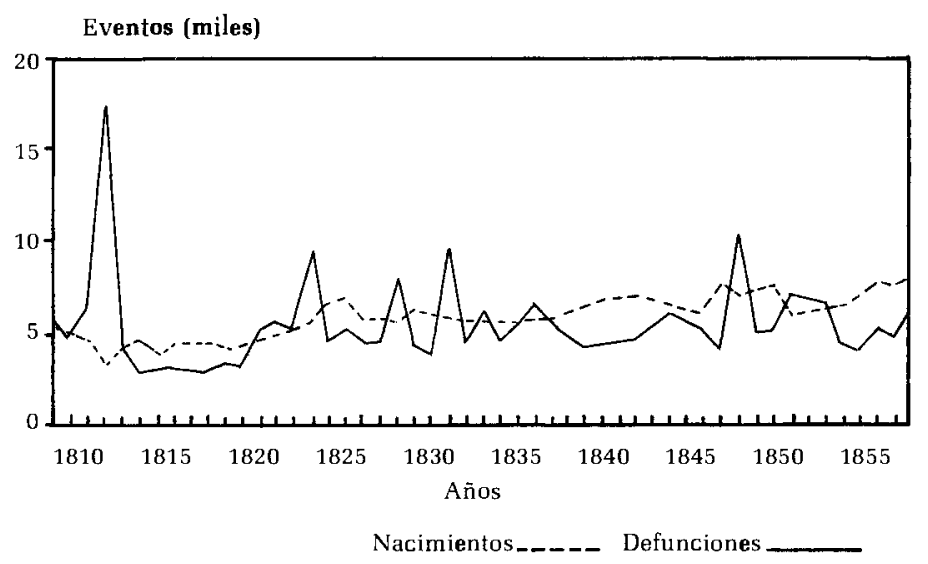

trofes naturales y sociules que produjeron un crecimiento demográfico muy débil, de manera que algunos de los aumentos de población registrados en años específicos pueden encontrar una explicación más directa en los movimientos migratorios y no en la natalidad. Establecer el monto de la población residente en la Ciudad de México durante 1833 implica tener en cuenta lo anteriormente señalado y obliga a recurrir a las estimaciones existentes para años cercanos. Puesto que no todas las estimaciones encontradas presentan el mismo grado de confiabilidad, nos vimos obligados a seleccionar los datos que, a nuestro juicio, resultan más apropiados: supusimos que los datos que provienen de los Censos Nacionales, del Ayuntamiento, el Tribunal del Consulado, la Sociedad de Geografía y Estadística y el Padrón del Juzgado de Policía, por ejemplo, pueden ser tomados con mayor confianza que aquéllos en los que se desconoce la fuente o los procedimientos empleados por los autores. ${ }^{3}$

Después de varios ensayos y a través de diversos métodos, ${ }^{4}$

${ }^{3}$ Ver en los anexos el cuadro que resume las estimaciones de población de la Ciudad de México para el periodo considerado.

${ }^{4}$ Se empleó el método "spline" para estimar la población total. Tomando como base los datos relativos al total de nacimientos y a la estructura de las defunciones registradas, y con el apoyo de las "poblaciones estables", se estableció la estructura relativa de la población, de acuerdo al sexo y la edad, y se derivaron tasas brutas de natalidad y mortalidad, tasas de crecimiento y tablas de vida para cada sexo. 
CUADRO 1

Ciudad de México: población estimada por edad y sexo, 1833

\begin{tabular}{|c|c|c|c|c|c|}
\hline \multirow[b]{2}{*}{ Edad } & \multirow[b]{2}{*}{ Total } & \multicolumn{2}{|c|}{ Hombres } & \multicolumn{2}{|c|}{ Mujeres } \\
\hline & & Absolutos & Porcentaje & Absolutos & Porcentaje \\
\hline Total & 129248 & 63523 & 49.1 & 65725 & 50.9 \\
\hline 0 & 5131 & 2556 & 2.0 & 2575 & 2.0 \\
\hline $1-4$ & 16195 & 8012 & 6.2 & 8183 & 6.3 \\
\hline $5-9$ & 17315 & 8573 & 6.6 & 8742 & 6.8 \\
\hline $10-14$ & 15251 & 7563 & 5.9 & 7688 & 6.0 \\
\hline $15-19$ & 13432 & 6674 & 5.2 & 6758 & 5.2 \\
\hline $20-24$ & 11691 & 5812 & 4.5 & 5879 & 4.6 \\
\hline $25-29$ & 10073 & 5004 & 3.9 & 5069 & 3.9 \\
\hline $30-34$ & 8613 & 4274 & 3.3 & 4339 & 3.4 \\
\hline $35-39$ & 7298 & 3611 & 2.8 & 3687 & 2.9 \\
\hline $40-44$ & 6115 & 3004 & 2.3 & 3111 & 2.4 \\
\hline $45-49$ & 5061 & 2454 & 1.9 & 2607 & 2.0 \\
\hline $50-54$ & 4100 & 1953 & 1.5 & 2147 & 1.7 \\
\hline $55-59$ & 3213 & 1498 & 1.1 & 1715 & 1.3 \\
\hline $60-64$ & 2386 & 1086 & 0.8 & 1300 & 1.0 \\
\hline $65-69$ & 1634 & 723 & 0.5 & 91 & 0.7 \\
\hline $70-74$ & 996 & 426 & 0.3 & 570 & 0.4 \\
\hline $75-79$ & 506 & 208 & 0.2 & 298 & 0.2 \\
\hline 80 y más & 238 & 92 & 0.1 & 146 & 0.1 \\
\hline
\end{tabular}

GRÁFICA 2

Población estimada de la Ciudad de México, 1833

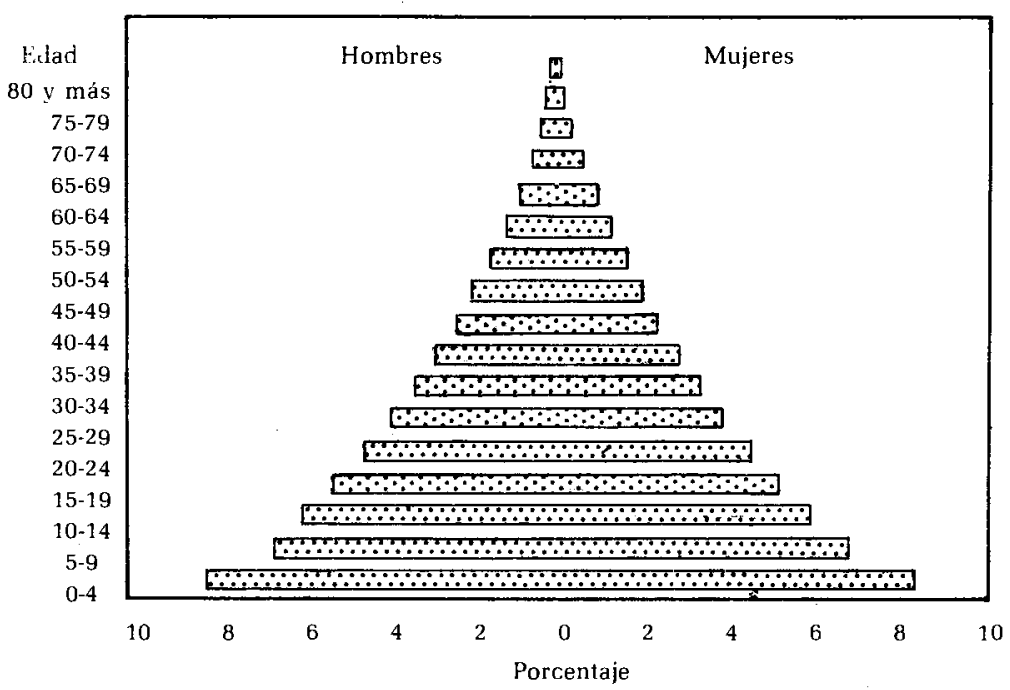


se estimó la estructura de la población por edad y sexo para 1833 , misma que sirvió de base para inferir el nivel de la mortalidad.

\section{La mortalidad general en $\mathbf{1 8 3 3}$}

Los graves problemas políticos, sociales y económicos que padeció la República mexicana (y la Ciudad de México) durante el siglo XIX, aunados a las grandes epidemias y hambrunas del periodo, combinaron sus efectos para producir una gran mortalidad.

La gravedad de las endemias y de los brotes epidémicos que se sucedieron en el país en ese periodo fue provocada, en gran medida, por la desnutrición aguda o crónica del pueblo mexicano: “. . su inadecuada dieta los predispone a enfermar por la escasez, el alto precio y las malas condiciones de las carnes en una ciudad en la que los vegetales son más aguados que nutritivos", escribiría Montaña (citado por Bustamante, 1982).

Si se analizan los principales hechos relacionados con la elevada mortalidad del país en el siglo XIX y los datos relacionados con las enfermedades que se desarrollaron en el periodo, se llega a la conclusión de que la patología infecciosa y contagiosa parece ser una prolongación de las grandes "pestilencias" universales de los siglos XVI y XVII. De hecho, Navarro y Noriega señalaba que “. . uno no encuentra que este reino (Nueva España) esté tan poblado como debería estarlo, excepto en una o dos provincias, porque la miseria en la que el pueblo vive, los desafortunados efectos de su educación y las hambres y las epidemias han causado la desaparición de un gran número de personas" (Navarro y Noriega, 1969, 1:289).

Hay algunas estimaciones que nos muestran los elevados niveles de la mortalidad de la época. En 1879, por ejemplo, Ildefonso Velasco, presidente del Consejo Superior de Salubridad, señalaba que la mortalidad predominante entre los habitantes de la capital correspondía a menores de un año, y que la de los niños de uno a tres era también considerable. Sus cálculos muestran que $50.4 \%$ de las defunciones generales correspondía a las de los menores de 12 años (Ildefonso Velasco, 1880).

Para 1879 Reyes (1880) anotaba la existencia de 250000 habitantes, en tanto que Ildefonso Velasco (1880) señala un total de 10223 defunciones en ese año, cifras con las que se estima una tasa bruta de mortalidad de 40.89 por mil. Bustamante, por su lado, estima que la mortalidad general de la Ciudad de México era de 49.9 defunciones por cada mil habitantes en el periodo de 1891 a 1900 .

Entre las diversas causas de muerte sobresalen algunas enfer- 
medades transmisibles como la viruela, el tifo exantemático, la tifoidea y otras gastrointestinales, el sarampión, la fiebre amarilla, el paludismo y el cólera.

En los registros parroquiales generalmente aparece identificada la causa del fallecimiento, aunque, como es lógico suponer, la mayoría de las causas declaradas no contaron con una certificación médica, y se registraron una gran cantidad de afecciones cuyos nombres no encuentran sú correspondiente en la actualidad. En los anexos incluimos la lista completa de las causas de deceso encontradas en los archivos parroquiales revisados. Fueron agrupadas bajo cinco grandes grupos, de acuerdo con una de las clasificaciones propuestas por la Organización de las Naciones Unidas, pues aunque ésta obedece a un criterio clínico individual (y sólo debería emplearse en inferencias de ese carácter, en tanto los tipos sociales de causas deberían agruparse bajo otros sistemas clasificatorios), resultó de utilidad para los objetivos de trabajo. ${ }^{5}$

Cabe mencionar que en el México del siglo XIX (y aun en el de la actualidad) las causas que provocaron (y siguen provocando) la mayor parte de los decesos entre los jóvenes pertenecen al Grupo i (enfermedades infecciosas y parasitarias, gripe, neumonía, bronquitis y otras enfermedades del aparato respiratorio), y que un análisis más profundo de la mortalidad por causas en el periodo permitiría establecer algunas de las relaciones existentes entre este fenómeno y las condiciones materiales, sanitarias y socioeconómicas asociadas a determinados tipos de decesos; pero tal análisis escapa a los objetivos del presente documento.

En 1833 se registraron 9445 defunciones en las parroquias de la Ciudad de México, ${ }^{6}$ es decir, $155 \%$ más que el año anterior (cuando no hubo cólera); $44.5 \%$ de los decesos ocurrió en el sexo masculino y el $28.3 \%$ del total correspondió a la mortalidad infantil de ambos sexos, pero resalta una sobremortalidad masculina entre los menores de 5 años de edad $33.6 \%$ de los hombres falleció antes de su quinto aniversario, mientras que "sólo" $24.2 \%$ de las mujeres murieron en igual circunstancia). La mortalidad adulta más elevada se presenta en los grupos de edades 30-34 y 40-44 de ambos sexos.

Al calcular las tasas centrales de mortalidad y las probabilidades de fallecer, se observaron marcadas irregularidades que pare-

${ }^{5}$ Ver anexos.

${ }^{6}$ San Pablo Apóstol, San Miguel Arcángel, San Sebastián, Santo Tomás la Palma, Santa Cruz y Soledad, Santa Ana, San José de Nuestra Señora del Sagrado Corazón de Jesús, Santa Catarina, Santa Veracruz, Purísima Concepción y Salto del Agua, Santa María la Redonda, Sagrario Metropolitano. 
CUADRO 2

Ciudad de México: defunciones registradas en 1833

\begin{tabular}{|c|c|c|c|c|c|}
\hline \multirow[b]{2}{*}{ Edad } & \multirow[b]{2}{*}{ Total } & \multicolumn{2}{|c|}{ Hombres } & \multicolumn{2}{|c|}{ Mujeres } \\
\hline & & Absolutos & Porcentaje & Absolutos & Porcentaje \\
\hline Total & 9445 & 4205 & 44.5 & 5240 & 55.5 \\
\hline 0 & 1021 & 560 & 5.9 & 461 & 4.9 \\
\hline 1 & 701 & 387 & 4.1 & 314 & 3.3 \\
\hline 2 & 504 & 239 & 2.5 & 265 & 2.8 \\
\hline 3 & 271 & 141 & 1.5 & 130 & 1.4 \\
\hline 4 & 177 & 85 & 0.9 & 92 & 1.0 \\
\hline $5-9$ & 447 & 253 & 2.7 & 194 & 2.0 \\
\hline $10-14$ & 213 & 102 & 1.1 & 111 & 1.2 \\
\hline $15-19$ & 239 & 115 & 1.2 & 124 & 1.3 \\
\hline $20-24$ & 548 & 245 & 2.6 & 303 & 3.2 \\
\hline $25-29$ & 557 & 219 & 2.3 & 338 & 8.6 \\
\hline $30-34$ & 983 & 423 & 4.5 & 560 & 5.9 \\
\hline $35-39$ & 415 & 177 & 1.9 & 238 & 2.5 \\
\hline $40-44$ & 817 & 328 & 3.5 & 489 & 5.2 \\
\hline $45-49$ & 321 & 125 & 1.3 & 196 & 2.1 \\
\hline $50-54$ & 721 & 261 & 2.8 & 460 & 4.9 \\
\hline $55-59$ & 208 & 95 & 1.0 & 113 & 1.2 \\
\hline $60-64$ & 759 & 276 & 2.9 & 483 & 5.1 \\
\hline $65-69$ & 176 & 60 & 0.6 & 116 & 1.2 \\
\hline $70-74$ & 145 & 35 & 0.4 & 110 & 1.2 \\
\hline $75-79$ & 40 & 12 & 0.1 & 28 & 0.3 \\
\hline $80-84$ & 109 & 39 & 0.4 & 70 & 0.7 \\
\hline 85 y más & 73 & 28 & 0.3 & 45 & 0.5 \\
\hline
\end{tabular}

cen responder a problemas de declaración de la edad en el momento del deceso. Por eso, a fin de corregir los resultados y "reconstruir" la mortalidad de la población bajo estudio, se recurrió al "logito" de Brass." Las series estimadas de sobrevivientes permitieron calcular las tablas de vida abreviadas de la población masculina y femenina de 1832 y 1833 (véanse cuadros 3 a 6).

En 1832, la población masculina registró una esperanza de vida al nacimiento de 33.92 años, en tanto que la población femenina mostró una de 35.78 años ( 1.86 años más). En los primeros años de edad la esperanza de vida femenina es mayor que la masculina, pero a partir de los 15 años la relación se invierte, mostrando una sobremortalidad femenina. En contraste, en 1833 la esperanza de

${ }^{7}$ Se tomó como modelo la serie de sobrevivientes de las tablas de vida de 1832, generadas a través de poblaciones estables. Como "entradas" al modelo se tomaron los promedios de los datos obtenidos (de 1 a 35 años y de 40 a 80 años). 
CUADRO 3

Tabla de vida de la población masculina de la Ciudad de México, 1832

\begin{tabular}{rrrrrrr}
\hline$X$ & \multicolumn{1}{c}{$l_{x}$} & \multicolumn{1}{c}{$d_{x}$} & ${ }_{n} q_{x}$ & ${ }_{n} L_{x}$ & $T_{x}$ & $\mathbf{e}_{x}$ \\
\hline 0 & 100000 & 22682 & 0.226820 & 0.868828 & 33.923971 & 33.92 \\
1 & 77318 & 10683 & 0.138170 & 2.821613 & 33.055143 & 42.75 \\
5 & 66635 & 2498 & 0.037488 & 3.269300 & 30.233530 & 45.37 \\
10 & 64137 & 1739 & 0.027114 & 3.163375 & 26.964230 & 42.04 \\
15 & 62398 & 2339 & 0.037485 & 3.061425 & 23.800855 & 38.14 \\
20 & 60059 & 3198 & 0.053248 & 2.923000 & 20.739430 & 34.53 \\
25 & 56861 & 3381 & 0.059461 & 2.758525 & 17.816430 & 31.33 \\
30 & 53480 & 3676 & 0.068736 & 2.582100 & 15.057905 & 28.16 \\
35 & 49804 & 4027 & 0.080857 & 2.389525 & 12.475805 & 25.05 \\
40 & 45777 & 4494 & 0.098172 & 2.176500 & 10.086280 & 22.03 \\
45 & 41283 & 4770 & 0.115544 & 1.944900 & 7.909780 & 19.16 \\
50 & 36513 & 5373 & 0.147153 & 1.691325 & 5.964880 & 16.34 \\
55 & 31140 & 5668 & 0.182017 & 1.415300 & 4.273555 & 13.72 \\
60 & 25472 & 6244 & 0.245132 & 1.117500 & 2.858255 & 11.22 \\
65 & 19228 & 6177 & 0.321250 & 0.806975 & 1.740755 & 9.05 \\
70 & 13051 & 5562 & 0.426174 & 0.513500 & 0.933780 & 7.15 \\
75 & 7489 & 4225 & 0.564161 & 0.268700 & 0.420280 & 5.61 \\
80 más & 3264 & 3264 & 1.000000 & 0.151580 & 0.151580 & 4.64 \\
\hline
\end{tabular}

CUADRO 4

Tabla de vida de la población femenina de la Ciudad de México, 1832

\begin{tabular}{rrrrrrrr}
\hline$X$ & \multicolumn{1}{c}{$l_{x}$} & \multicolumn{1}{c}{${ }_{n} d_{x}$} & ${ }_{n} q_{x}$ & ${ }_{n} L_{x}$ & $T_{x}$ & $e_{x}$ \\
\hline 0 & 100000 & 14449 & 0.144990 & 0.905883 & 35.782283 & 35.78 \\
1 & 85501 & 11995 & 0.140291 & 3.104791 & 34.876400 & 40.79 \\
5 & 73506 & 3217 & 0.043765 & 3.594875 & 31.771609 & 43.22 \\
10 & 70289 & 2470 & 0.035141 & 3.452700 & 28.176374 & 40.09 \\
15 & 67819 & 3208 & 0.047302 & 3.310750 & 24.724034 & 36.46 \\
20 & 64611 & 3934 & 0.060887 & 3.132200 & 21.413284 & 31.57 \\
25 & 60677 & 4255 & 0.070125 & 2.927475 & 18.281084 & 30.13 \\
30 & 56422 & 4575 & 0.081085 & 2.706725 & 15.353609 & 27.21 \\
35 & 51847 & 4630 & 0.089301 & 2.476600 & 12.646884 & 24.39 \\
40 & 47217 & 4833 & 0.102357 & 2.240025 & 10.170284 & 21.54 \\
45 & 42384 & 4733 & 0.111669 & 2.000875 & 7.930259 & 18.71 \\
50 & 37651 & 5500 & 0.146078 & 1.745050 & 5.929384 & 15.75 \\
55 & 32151 & 6034 & 0.187677 & 1.456700 & 4.184334 & 13.01 \\
60 & 26117 & 7007 & 0.268293 & 1.130675 & 2.727634 & 10.44 \\
65 & 19110 & 6729 & 0.352119 & 0.787275 & 1.596959 & 8.36 \\
70 & 12381 & 5911 & 0.477425 & 0.471275 & 0.809694 & 6.54 \\
75 & 6470 & 3979 & 0.614992 & 0.224025 & 0.338409 & 5.23 \\
80 y más & 2491 & 2491 & 1.000000 & 0.114384 & 0.114384 & 4.59 \\
\hline
\end{tabular}


CUADRO 5

Tabla de vida de la población masculina de la Ciudad de México, 1833 Todas las causas de muerte

\begin{tabular}{|c|c|c|c|c|c|c|}
\hline$X$ & $l_{x}$ & ${ }_{n} d_{x}$ & ${ }_{n} q_{x}$ & ${ }_{n} L_{x}$ & $T_{x}$ & $\mathbf{e}_{x}$ \\
\hline 0 & 100000 & 21374 & 0.213740 & 0.873973 & 17.015259 & 17.02 \\
\hline 1 & 78626 & 25275 & 0.321459 & 2.499972 & 16.141286 & 20.53 \\
\hline 5 & 53351 & 6022 & 0.112875 & 2.517000 & 13.641314 & 25.57 \\
\hline 10 & 47329 & 4052 & 0.085613 & 2.265150 & 11.124314 & 23.50 \\
\hline 15 & 43277 & 5190 & 0.119925 & 2.034100 & 8.859164 & 20.47 \\
\hline 20 & 38087 & 6522 & 0.171240 & 1.741300 & 6.825064 & 17.92 \\
\hline 25 & 31565 & 6075 & 0.192460 & 1.426375 & 5.083764 & 16.11 \\
\hline 30 & 25490 & 5619 & 0.220439 & 1.134025 & 3.657389 & 14.35 \\
\hline 35 & 19871 & 5032 & 0.253233 & 0.867750 & 2.523364 & 12.70 \\
\hline 40 & 14839 & 4379 & 0.295101 & 0.632475 & 1.655614 & 11.16 \\
\hline 45 & 10460 & 3456 & 0.330402 & 0.436600 & 1.023139 & 9.78 \\
\hline 50 & 7004 & 2740 & 0.391205 & 0.281700 & 0.586539 & 8.37 \\
\hline 55 & 4264 & 1906 & 0.446998 & 0.165550 & 0.304839 & 7.15 \\
\hline 60 & 2358 & 1274 & 0.540288 & 0.086050 & 0.139289 & 5.91 \\
\hline 65 & 1084 & 686 & 0.632841 & 0.037050 & 0.053239 & 4.91 \\
\hline 70 & 398 & 294 & 0.738693 & 0.012550 & 0.016189 & 4.07 \\
\hline 75 & 104 & 89 & 0.855769 & 0.002975 & 0.003639 & 3.50 \\
\hline 80 y más & 15 & 15 & 1.000000 & 0.000664 & 0.000664 & 4.43 \\
\hline
\end{tabular}

CUADRO 6

Tabla de vida de la población femenina de la Ciudad de México, 1833 Todas las causas de muerte

\begin{tabular}{rrrrrrr}
\hline$X$ & \multicolumn{1}{c}{$l_{x}$} & \multicolumn{1}{c}{${ }_{n} d_{x}$} & ${ }_{n} q_{x}$ & ${ }_{n} L_{x}$ & $T_{x}$ & $e_{x}$ \\
\hline 0 & 100000 & 5744 & 0.057440 & 0.958362 & 15.631381 & 15.63 \\
1 & 94256 & 29384 & 0.311747 & 2.969549 & 14.673019 & 15.57 \\
5 & 64872 & 11087 & 0.170906 & 2.966425 & 11.703470 & 18.04 \\
10 & 53785 & 8354 & 0.155322 & 2.480400 & 8.737045 & 16.24 \\
15 & 45431 & 9974 & 0.219542 & 2.022200 & 6.256645 & 13.77 \\
20 & 35457 & 10226 & 0.288406 & 1.517200 & 4.234445 & 11.94 \\
25 & 25231 & 8358 & 0.331259 & 1.052600 & 2.717245 & 10.77 \\
30 & 16873 & 6241 & 0.369881 & 0.687625 & 1.664645 & 9.87 \\
35 & 10632 & 4130 & 0.388450 & 0.428350 & 0.977020 & 9.19 \\
40 & 6502 & 2706 & 0.416180 & 0.257450 & 0.548670 & 8.44 \\
45 & 3796 & 1617 & 0.425975 & 0.149375 & 0.291220 & 7.67 \\
50 & 2179 & 1088 & 0.499312 & 0.081750 & 0.141845 & 6.51 \\
55 & 1091 & 621 & 0.569203 & 0.038025 & 0.060095 & 5.51 \\
60 & 470 & 323 & 0.687234 & 0.015425 & 0.021070 & 4.48 \\
65 & 147 & 114 & 0.775510 & 0.004500 & 0.005645 & 3.84 \\
70 & 33 & 29 & 0.878788 & 0.000925 & 0.001145 & 3.47 \\
75 & 4 & 4 & 1.000000 & 0.000220 & 0.000220 & 5.51 \\
80 y más & - & - & - & - & - & - \\
\hline
\end{tabular}




\section{GRÁFICA 3}

Ciudad de México. Probabilidades de fallecer de ia población masculina, 1832 y 1833

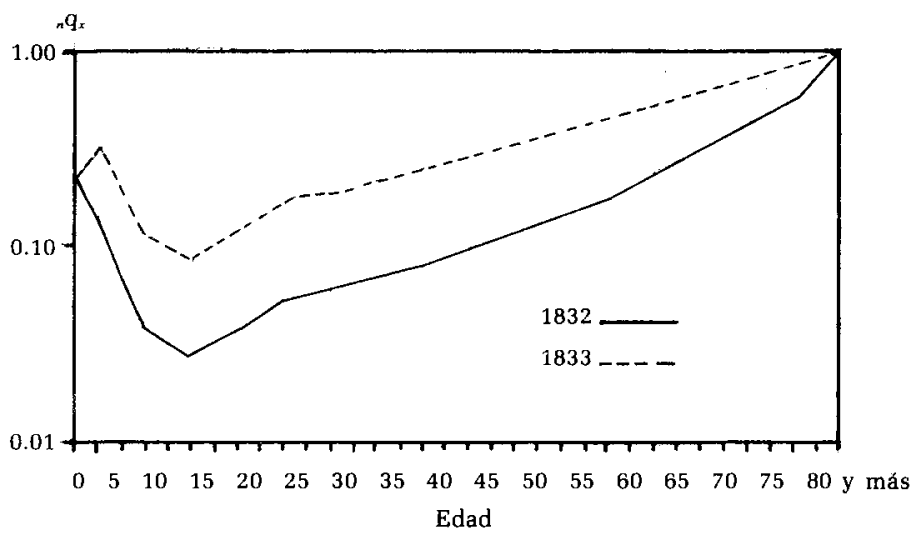

vida masculina es permanentemente superior a la femenina; los valores alcanzados al nacimiento son de 17.02 para los hombres y de 15.63 para las mujeres.

Entre los años 1832 y 1833 este indicador sufrió un descenso de grandes magnitudes: 16.9 años en el sexo masculino y 20.13 en el caso del sexo femenino.

\section{GRÁFICA 4}

Ciudad de México. Probabilidades de fallecer de la población femenina, 1832 y 1833

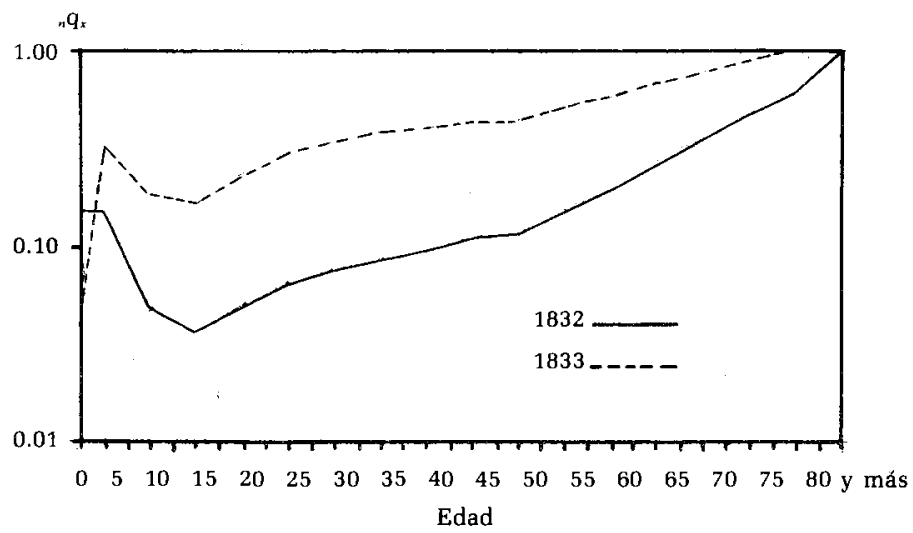


Las probabilidades de fallecer también se vieron modificadas; si bien durante el primer año de vida las ${ }_{n} \mathrm{q}_{x}$ son menores en 1833 respecto a 1832, en el resto de las edades la situación se invierte: las probabilidades de morir fueron considerablemente mayores en el último año. Diferencias tan notorias en ambos indicadores $\left(e^{0} y_{n} q_{x}\right)$ entre uno y otro año sólo pueden ser explicadas por la presencia de una epidemia o una catástrofe de grandes magnitudes, como la que ahora nos ocupa.

\section{La mortalidad por cólera en la Ciudad de México, 1833}

Para conocer el significado que el cólera morbus tuvo en el nivel de mortalidad, se hace necesario realizar un somero análisis que lleve a estimar el nivel que este fenómeno demográfico hubiera alcanzado de no haberse presentado tal epidemia.

En la mayor parte de las parroquias de la Ciudad de México se llevaron registros más o menos rigurosos de la edad en el momento del deceso, el sexo del difunto y la causa del fallecimiento; en ocasiones se incluyeron datos relativos a la ocupación y al estado civil y, a veces, alguna información que el párroco considerara de interés. ${ }^{8}$

En el conjunto de las parroquias se registró un total de 6165 defunciones ocasionadas por cólera $(44.1 \%$ hombres y $55.9 \%$ mujeres), lo que representa $65.3 \%$ de las defunciones generales egistradas en esta ciudad. Es posible, sin embargo, que muchas de las defunciones registradas bajo esta causa, en realidad, fueran ocasionadas por otro tipo de afecciones gastrointestinales, pero como ocurrieron durante el periodo de epidemia se supuso que habían sido provocadas por ella.

Del total de hombres fallecidos por esta causa, $7.1 \%$ lo hizo antes de alcanzar el primer año de vida y $24.9 \%$ antes de cumplir cinco. Entre los adultos, los grupos de edades mayormente afectados fueron el de 30 a 34 y el de 40 a 44 años (con proporciones de 11.6 y $9.2 \%$, respectivamente).

Entre las mujeres, $4.5 \%$ falleció por cólera durante el primer año de vida, en tanto que $15 \%$ murió antes de alcanzar el quinto

${ }^{8}$ Para 1833 en el Sagrario Metropolitano no se registró la causa del deceso, pero al final del año el párroco observó que durante la epidemia de cólera sucumbieron por esta causa un total de 1522 personas (445 de las cuales eran del sexo masculinol. Las parroquias de la Santa Catarina y la Santa Veracruz tampoco presentan información sobre la causa de la muerte: en este caso supusimos que la proporción de defunciones por cólera y su distribución por sexo y edad era similar a la observada en el resto de la ciudad. 


\section{CUADRO 7}

Ciudad de México: defunciones ocasionadas por el cólera, 1833

\begin{tabular}{crrrrrr}
\hline & & \multicolumn{2}{c}{ Hombres } & & \multicolumn{2}{c}{ Mujeres } \\
\cline { 3 - 4 } \cline { 6 - 7 } Edad & Total & Absolutos & Porcentaje & & Absolutos & Porcentaje \\
\hline Total & 6 & 165 & 219 & 44.1 & 3446 & 55.9 \\
0 & 348 & 192 & 3.1 & 156 & 2.5 \\
1 & 275 & 181 & 2.9 & & 94 & 1.5 \\
2 & 260 & 134 & 2.2 & & 126 & 2.0 \\
3 & 180 & 100 & 1.6 & & 80 & 1.3 \\
4 & 129 & 68 & 1.1 & & 61 & 1.0 \\
$5-9$ & 336 & 191 & 3.1 & 145 & 2.4 \\
$10-14$ & 168 & 79 & 1.3 & & 89 & 1.4 \\
$15-19$ & 157 & 78 & 1.3 & & 79 & 1.3 \\
$20-24$ & 408 & 176 & 2.9 & & 232 & 3.8 \\
$25-29$ & 429 & 166 & 2.7 & & 263 & 4.3 \\
$30-34$ & 743 & 315 & 5.1 & & 428 & 6.9 \\
$35-39$ & 293 & 112 & 1.8 & & 181 & 3.0 \\
$40-44$ & 629 & 251 & 4.1 & & 378 & 6.1 \\
$45-49$ & 224 & 94 & 1.5 & & 130 & 2.1 \\
$50-54$ & 538 & 204 & 3.3 & & 334 & 5.4 \\
$55-59$ & 136 & 56 & 0.9 & & 80 & 1.3 \\
$60-64$ & 563 & 205 & 3.3 & 358 & 5.8 \\
$65-69$ & 120 & 42 & 0.7 & 78 & 1.3 \\
$70-74$ & 87 & 19 & 0.3 & 68 & 1.1 \\
$75-79$ & 18 & 7 & 0.1 & & 11 & 0.2 \\
$80-84$ & 78 & 27 & 0.4 & & 51 & 0.8 \\
85 y más & 46 & 22 & 0.4 & 24 & 0.4 \\
\hline & & & & & &
\end{tabular}

aniversario. La mayor porporción de decesos entre los adultos de este sexo se encontró en los grupos de edades 30-34, 40-44 y 60-64 (con cifras de $12.4,11.0$ y $10.4 \%$, respectivamente).

Como en el caso de la mortalidad general, se procedió al cálculo de las tasas centrales y las probabilidades de fallecer para cada sexo por separado y para los dos grupos de causas de muerte aquí consideradas: cólera morbus y otras causas. Al observar los "picos" o alzas en las edades que comprenden el dígito cero, se procedió al cálculo de la serie de sobrevivientes para obtener los logitos correspondientes. ${ }^{9}$ Una vez obtenida la nueva serie de sobrevivientes para cada caso, se calcularon las tablas de vida correspondientes.

${ }^{9}$ Nuevamente se tomó como estándar a la población estable de 1832 y las entradas al modelo de Brass fueron las mismas: los promedios de las observaciones de 1 a 35 y de 40 a 80 , respectivamente. 
En los dos casos analizados, las mujeres presentaron menores expectativas de vida que los hombres. Por lo que a las defunciones ocasionadas por cólera se refiere, los hombres mostraron una esperanza de vida al nacimiento de 29.8 años, en tanto que las mujeres alcanzaron la cifra de 26.2, es decir, 3.6 años menos. La esperanza de vida a los cinco años (la más elevada) fue de 34.2 en el sexo masculino y de 27.1 en el femenino (una diferencia de 7.1 años).

Por lo que respecta a las restantes causas de muerte, las diferencias también resultaron notorias: la esperanza de vida al nacimiento fue de 40.2 años entre los hombres y de 36.3 entre las mujeres, y la correspondiente a los cinco años de edad resultó ser de 49.2 en el sexo masculino y de 43.0 en el femenino, acusando diferencias de 3.9 y 6.2 años menos entre las mujeres, respectivamente.

La tendencia de las probabilidades de fallecer por cada una de las causas mostró también algunos hechos interesantes: entre los hombres, este indicador alcanzó la cifra de $107 \%$ en el caso de la mortalidad por cólera y de $184 \%$ en el de las restantes causas de muerte (77 defunciones más por cada mil nacidos vivos). Hay que destacar el hecho de que ésta es la única edad en la que la ${ }_{n} q_{x}$ por cólera resultó menor que la del resto de las causas.

La misma situación se manifestó en el caso de las mujeres: la ${ }_{n} q_{x}$ por cólera fue siempre mayor que la de las demás causas de deceso, a excepción del primer grupo de edades (menores de un año), en donde este indicador alcanzó las cifras de $42 \%$ en el caso del cólera y de $132 \%$ en el de las demás causas (90 defunciones más por cada mil nacidas vivas).

Este breve análisis no permite ver con claridad el peso que la epidemia de cólera tuvo en el nivel de la mortalidad general, ni saber cuál hubiera sido la tendencia de este fenómeno de no haberse presentado la epidemia. Se hace necesario entonces llevar a cabo otro tipo de análisis, aprovechando la oportunidad que nos brinda la tabla de mortalidad, específicamente a través de: a) las probabilidades de fallecer, por causa o grupos de causas y b) los efectos de la esperanza de vida al eliminar cualquier causa o grupo de causas.

Siguiendo a Pérez Astorga (1982) calculamos la distribución relativa de las defunciones por cada una de las dos causas o grupos de causas, ajustándola en los grupos de edades en los que no parecía haber lógica, ${ }^{10} \mathrm{y}$ la distribución obtenida fue aplicada a las defunciones de la tabla de mortalidad general de 1833 , obteniendo las defunciones esperadas por causa. Éstas se dividieron

\footnotetext{
${ }^{10}$ En los grupos de edades "problemáticos" consideramos que la distribución sería semejante a los promedios observados entre los restantes grupos de edades.
} 
CUADRO 8

Ciudad de México: defunciones ocasionadas por cualquier causa diferente al cólera, 1833

\begin{tabular}{|c|c|c|c|c|c|}
\hline \multirow[b]{2}{*}{ Edad } & \multirow[b]{2}{*}{ Total } & \multicolumn{2}{|c|}{ Hombres } & \multicolumn{2}{|c|}{ Mujeres } \\
\hline & & Absolutos & Porcentaje & Absolutos & Porcentaje \\
\hline Total & 3280 & 1486 & 45.3 & 1794 & 54.7 \\
\hline 0 & 673 & 368 & 11.2 & 305 & 9.3 \\
\hline $1-4$ & 809 & 369 & 11.2 & 440 & 13.4 \\
\hline $5-9$ & 111 & 62 & 1.9 & 49 & 1.5 \\
\hline $10-14$ & 45 & 23 & 0.7 & 22 & 0.7 \\
\hline $15-19$ & 82 & 37 & 1.1 & 45 & 1.4 \\
\hline $20-24$ & 140 & 69 & 2.1 & 71 & 2.2 \\
\hline $25-29$ & 128 & 53 & 1.6 & 75 & 2.3 \\
\hline $30-34$ & 240 & 108 & 3.3 & 132 & 4.0 \\
\hline $35-39$ & 122 & 65 & 2.0 & 57 & 1.7 \\
\hline $40-44$ & 188 & 77 & 2.3 & 111 & 3.4 \\
\hline $45-49$ & 97 & 31 & 1.0 & 66 & 2.0 \\
\hline $50-54$ & 183 & 57 & 1.7 & 126 & 3.8 \\
\hline $55-59$ & 72 & 39 & 1.2 & 33 & 1.0 \\
\hline $60-64$ & 196 & 71 & 2.2 & 125 & 3.8 \\
\hline $65-69$ & 56 & 18 & 0.5 & 38 & 1.2 \\
\hline $70-74$ & 58 & 16 & 0.5 & 42 & 1.3 \\
\hline $75-79$ & 22 & 5 & 0.2 & 17 & 0.5 \\
\hline $80-84$ & 31 & 12 & 0.4 & 19 & 0.6 \\
\hline 35 y más & 27 & 6 & 0.2 & 21 & 0.6 \\
\hline
\end{tabular}

por los sobrevivientes a la edad exacta $x$ de la misma tabla, a fin de obtener la probabilidad eventual de fallecer por cada grupo de causas de defunción determinado al llegar a la edad exacta $x$ y antes de cumplir la edad $\mathrm{x}+\mathrm{n}$.

Así, tenemos que:

$$
{ }_{n} \mathrm{q}_{x}^{i}=\frac{{ }_{n} \mathrm{~d}_{x}^{i}}{\mathrm{l}_{x}}
$$

donde i representa el grupo de causas de deceso específico.

Posteriormente y con el objeto de medir el efecto de las causas de defunción particulares sobre la esperanza de vida, se tomaron como base los siguientes supuestos: a) Las defunciones por cualquier grupo de causas, de personas de edad $x$ se distribuyen uniformemente a lo largo del año. ${ }^{11}$ b) Quienes no fallecen por un

\footnotetext{
11 En realidad la epidemia de cólera estuvo presente en la Ciudad de México durante los meses de julio a diciembre. es decir, durante la segunda mitad del pe-
} 
grupo de causas determinado, tienen la misma posibilidad de morir por los otros grupos de causas que el resto de la población. c) Al eliminarse un grupo determinado de causas, las probabilidades de fallecer por los otros grupos de causas no se modifican. ${ }^{12}$

Tomando en cuenta que las defunciones de cada grupo quinquenal de edades en la tabla de mortalidad pueden descomponerse en:

$$
{ }_{n} \mathrm{~d}_{x}={ }_{n} \mathrm{~d}_{x i}+{ }_{n} \mathrm{~d}_{x}^{i t}
$$

y considerando los supuestos anteriormente señalados, se obtiene la siguiente relación:

$$
{ }_{n} \mathrm{q}_{x}^{i}=\frac{{ }_{n} \mathrm{~d}_{x}-{ }_{n} \mathrm{~d}_{x}^{i}}{L_{x}-1 /{ }_{n} \mathrm{~d}_{x}^{i}}
$$

en donde

${ }_{n} d_{x}$ son las defunciones por causas distintas a las del grupo $i$ $L_{x}-1 / 2_{n} \mathrm{~d}_{x}^{i}$ son los sobrevivientes a la edad exacta $\mathrm{x}$, excepto quienes fallecieron por la causa i, considerando la mitad de las defunciones, puesto que se supone que ocurren uniformemente en el periodo.

Dado que ${ }_{n} \mathrm{p}_{x}=1-{ }_{n} \mathrm{q}_{x}^{i}$ la aproximación para el valor de la probabilidad de sobrevivencia ${ }_{n} \mathrm{p}_{x}$ sería:

$$
{ }_{n} p_{x}^{i}=\frac{l_{x+n} \frac{{ }_{n} d_{x}^{i}}{2}}{l_{x}-\frac{{ }_{n} d_{x}^{i}}{2}}
$$

Una vez obtenidas las probabilidades de sobrevivencia, se calcularon las restantes funciones de las tablas de vida abreviadas para cada sexo y grupo de causas de muerte.

Por lo que se refiere a las probabilidades de fallecer, por causas, observamos que en el sexo masculino el cólera presenta cifras

\footnotetext{
riodo, pero dada la calidad de la información disponible tuvimos que suponer esta condición.

${ }^{12}$ Estos dos últimos supuestos tampoco son totalmente ciertos, pues no estamos considerando aquí grupos de causas tales como "enfermedades infecciosas y parasitarias". Así, quien ha padecido cólera y no ha fallecido, probablemente está más propenso a morir en los meses siguientes por cualquier otra causa, que quien no ha sufrido este padecimiento. Sin embargo, debido al tipo de información disponible, debemos recurrir a tales supuestos.
} 
más elevadas en todas las edades, a excepción del primer grupo, en el que este indicador alcanza la cifra de $79 \%$ versus $146 \%$ en las defunciones por causa diferente ( 67 defunciones más por cada 1000 nacidos vivos). En los demás grupos de edades el cólera mantiene siempre una probabilidad de causar la muerte mayor que el resto de las causas.

En cuanto al sexo femenino, el cólera presenta una ${ }_{n} \mathrm{q}_{x}$ mayor que el resto de las causas en todos los grupos de edades, excepto en los dos primeros. Así, la ${ }_{1} \mathrm{q}_{0}$ por cólera es de $20 \%$, mientras que la de las demás causas es de $38 \%$, y la ${ }_{4} \mathrm{q}_{1}$ es de $154 \%$ para el cólera y de $184 \%$ para el resto de las causas (30 defunciones más).

Hay que resaltar el hecho de que la probabilidad general de fallecer (por cualquiera de las causas consideradas) es siempre mayor en el caso de las mujeres, frente a los hombres, a excepción del primero y del último grupos, en los que el sexo femenino alcanza 38 y $318 \%$ respectivamente, en tanto que el sexo masculino alcanza 146 y $347 \%$ (108 y 29 defunciones más, por cada mil habitantes, para cada edad respectivamente).

Esta misma situación prevalece cuando revisamos las probabilidades de fallecer por cólera: en los dos primeros grupos de edades las mujeres tienen menores " $\mathrm{q}_{x}$ que los hombres $(20 \%$ y $154 \%$ frente a 79 y $196 \%$, respectivamente); a partir de los cinco años de edad la relación se invierte.

Por lo que se refiere a las espectativas de vida observamos que, en el caso del sexo masculino, al suprimir la epidemia de cólera hay una ganancia de 12 años en la esperanza de vida al nacimiento y que esta diferencia se acrecienta hasta 23 años en la edad cinco, para iniciar el descen .). Conforme avanza la edad, la diferencia en años disminuye y, al llegar a los 80 años, las cifras obtenidas son semejantes en ambos casos.

En el sexo femenino, la esperanza de vida al nacimiento gana casi 11 años si se eliminan las defunciones producidas por el cólera. La diferencia aumenta hasta casi 23 años en la edad cinco, e inicia un descenso paulatino: al llegar a la edad 75 las cifras son semejantes.

Si se observan las tablas de vida correspondientes a todo tipo de defunciones, a excepción de las producidas por cólera, resaltan algunas diferencias interesantes entre ambos sexos: la esperanza de vida al nacimiento entre los hombres es de 39.13 años, en tanto que en las mujeres es de 36.38 , lo que significa una sobrevivencia masculina de 2.75 años. Esta diferencia se acentúa en el segundo grupo de edades (alcanzando un valor de 7.93 años), para iniciar su disminución en las últimas edades. 
CUADRO 9

Ciudad de México, 1833: tabla de vida de la población masculina (excluyendo las defunciones provocadas por cólera)

\begin{tabular}{rrrrrrr}
\hline$X$ & \multicolumn{1}{c}{$l_{x}$} & \multicolumn{1}{c}{${ }_{n} d_{x}$} & ${ }_{n} q_{x}$ & ${ }_{n} L_{x}$ & $T_{x}$ & $e_{x}$ \\
\hline 0 & 100000 & 14578 & 0.145783 & 0.905470 & 39.128189 & 39.13 \\
1 & 85422 & 13085 & 0.153186 & 3.073098 & 38.222719 & 44.75 \\
5 & 72337 & 2090 & 0.028897 & 3.564600 & 35.149621 & 48.59 \\
10 & 70247 & 1403 & 0.019974 & 3.477275 & 31.585021 & 44.96 \\
15 & 68844 & 2769 & 0.040224 & 3.372975 & 28.107746 & 40.83 \\
20 & 66075 & 3394 & 0.051365 & 3.218900 & 24.734771 & 37.43 \\
25 & 62681 & 3596 & 0.057371 & 3.044150 & 21.515871 & 34.33 \\
30 & 59085 & 3624 & 0.061330 & 2.863650 & 18.471721 & 31.26 \\
35 & 55461 & 4389 & 0.077328 & 2.665825 & 15.608071 & 28.14 \\
40 & 51172 & 4690 & 0.091650 & 2.441350 & 12.942246 & 25.29 \\
45 & 46482 & 4344 & 0.093450 & 2.215500 & 10.500896 & 22.59 \\
50 & 42138 & 4247 & 0.100792 & 2.000725 & 8.285396 & 19.66 \\
55 & 37891 & 5596 & 0.147692 & 1.754650 & 6.284671 & 16.59 \\
60 & 32295 & 5619 & 0.174005 & 1.474275 & 4.530021 & 14.03 \\
65 & 26676 & 6511 & 0.244076 & 1.171025 & 3.055746 & 11.46 \\
70 & 20165 & 5663 & 0.280822 & 0.866675 & 1.884721 & 9.35 \\
75 & 14502 & 5035 & 0.347222 & 0.0599225 & 1.018046 & 7.02 \\
80 y más & 9467 & & 1.000000 & 0.0418821 & 0.0418821 & 4.42 \\
\hline
\end{tabular}

CUADRO 10

Ciudad de México, 1833: tabla de vida de la población masculina (sólo defunciones por cólera)

\begin{tabular}{rrrrrrr}
\hline$X$ & \multicolumn{1}{c}{$l_{x}$} & \multicolumn{1}{c}{${ }_{n} d_{x}$} & ${ }_{n} q_{x}$ & ${ }_{n} L_{x}$ & $T_{x}$ & $e_{x}$ \\
\hline 0 & 100000 & 7881 & 0.078815 & 0.944329 & 26.835716 & 26.84 \\
1 & 92119 & 18042 & 0.195852 & 3.197390 & 25.891387 & 28.11 \\
5 & 74077 & 5978 & 0.080702 & 3.554400 & 22.693997 & 30.64 \\
10 & 68099 & 4559 & 0.066948 & 3.290975 & 19.139597 & 28.11 \\
15 & 63540 & 5270 & 0.082937 & 3.045250 & 15.848622 & 24.94 \\
20 & 58270 & 7343 & 0.126022 & 2.729925 & 12.803372 & 21.97 \\
25 & 50927 & 7276 & 0.142862 & 2.364450 & 10.073447 & 19.78 \\
30 & 43651 & 7371 & 0.168860 & 1.998275 & 7.708997 & 17.66 \\
35 & 36280 & 6880 & 0.189642 & 1.642000 & 5.710722 & 15.74 \\
40 & 29400 & 6534 & 0.222261 & 1.306650 & 4.068722 & 13.84 \\
45 & 22866 & 5922 & 0.258997 & 0.995250 & 2.762072 & 12.08 \\
50 & 16944 & 5413 & 0.319463 & 0.711875 & 1.766822 & 10.43 \\
55 & 11531 & 3968 & 0.344086 & 0.477350 & 1.054947 & 9.15 \\
60 & 7563 & 3261 & 0.431176 & 0.296625 & 0.577597 & 7.64 \\
65 & 4302 & 2105 & 0.489297 & 0.162475 & 0.280972 & 6.53 \\
70 & 2197 & 1305 & 0.593838 & 0.077225 & 0.118497 & 5.39 \\
75 & 892 & 618 & 0.692308 & 0.029150 & 0.041272 & 4.63 \\
80 y más & 274 & & 1.000000 & 0.012122 & 0.012122 & 4.42 \\
\hline
\end{tabular}


CUADRO 11

Ciudad de México, 1833: tabla de vida de la población femenina (excluyendo las defunciones provocadas por cólera)

\begin{tabular}{rrrrrrrr}
\hline$X$ & \multicolumn{1}{c}{$l_{x}$} & \multicolumn{1}{c}{${ }_{n} \mathrm{~d}_{x}$} & ${ }_{n} \mathrm{q}_{x}$ & ${ }_{n} L_{x}$ & $T_{x}$ & $\mathbf{e}_{x}$ \\
\hline 0 & 100000 & 3837 & 0.038373 & 0.971553 & 36.379633 & 36.38 \\
1 & 96163 & 17711 & 0.184175 & 3.360176 & 35.408080 & 36.82 \\
5 & 78452 & 3618 & 0.046123 & 3.832150 & 32.047904 & 40.85 \\
10 & 74834 & 2457 & 0.032834 & 3.680275 & 28.215754 & 37.70 \\
15 & 72377 & 4602 & 0.063583 & 3.503800 & 24.535479 & 33.90 \\
20 & 67775 & 5148 & 0.075962 & 3.260050 & 21.031679 & 31.03 \\
25 & 62627 & 5283 & 0.084353 & 2.999275 & 17.771629 & 28.38 \\
30 & 57344 & 5822 & 0.101532 & 2.721650 & 14.772354 & 25.76 \\
35 & 51522 & 5618 & 0.109039 & 2.435650 & 12.050704 & 23.39 \\
40 & 45904 & 5999 & 0.130695 & 2.145225 & 9.615054 & 20.95 \\
45 & 39905 & 5370 & 0.134561 & 1.861000 & 7.469829 & 18.72 \\
50 & 34535 & 5769 & 0.167040 & 1.582525 & 5.608829 & 16.24 \\
55 & 28766 & 5978 & 0.207807 & 1.288850 & 4.026304 & 14.00 \\
60 & 22788 & 5404 & 0.237143 & 1.004300 & 2.737454 & 12.01 \\
65 & 17384 & 4967 & 0.285714 & 0.745025 & 1.733154 & 9.97 \\
70 & 12417 & 3951 & 0.318182 & 0.522075 & 0.988129 & 7.96 \\
75 & 8466 & - & 1.000000 & 0.466054 & 0.466054 & 5.51 \\
80 y más & - & - & - & - & - & - \\
\hline
\end{tabular}

CUADRO 12

Ciudad de México, 1833: tabla de vida de la población femenina (sólo defunciones por cólera)

\begin{tabular}{rrrrrrrr}
\hline$X$ & \multicolumn{1}{c}{$l_{x}$} & \multicolumn{1}{c}{$d_{x}$} & ${ }_{n} q_{x}$ & ${ }_{n} L_{x}$ & $T_{x}$ & $e_{x}$ \\
\hline 0 & 100000 & 1982 & 0.019817 & 0.984987 & 22.432698 & 22.43 \\
1 & 98018 & 15060 & 0.153646 & 3.504086 & 21.447711 & 21.88 \\
5 & 82958 & 10829 & 0.130532 & 3.877175 & 17.943625 & 21.63 \\
10 & 72129 & 9123 & 0.126480 & 3.379875 & 14.066450 & 19.50 \\
15 & 63006 & 10455 & 0.165930 & 2.890425 & 10.686575 & 16.96 \\
20 & 52551 & 12011 & 0.228553 & 2.327275 & 7.796150 & 14.84 \\
25 & 40540 & 10846 & 0.267539 & 1.755850 & 5.468875 & 13.49 \\
30 & 29694 & 8776 & 0.295532 & 1.265300 & 3.713025 & 12.50 \\
35 & 20918 & 6479 & 0.309756 & 0.883925 & 2.447725 & 11.70 \\
40 & 14439 & 4665 & 0.323074 & 0.605325 & 1.563800 & 10.83 \\
45 & 9774 & 3235 & 0.331006 & 0.407825 & 0.958475 & 9.81 \\
50 & 6539 & 2545 & 0.389163 & 0.263325 & 0.550650 & 8.42 \\
55 & 3994 & 1753 & 0.439000 & 0.155875 & 0.287325 & 7.19 \\
60 & 2241 & 1251 & 0.558411 & 0.080775 & 0.131450 & 5.87 \\
65 & 990 & 630 & 0.636364 & 0.033750 & 0.050675 & 5.12 \\
70 & 360 & 261 & 0.724138 & 0.011475 & 0.016925 & 4.70 \\
75 & 99 & - & 1.000000 & 0.005450 & 0.005450 & 5.50 \\
80 y más & - & - & - & - & - & - \\
\hline
\end{tabular}




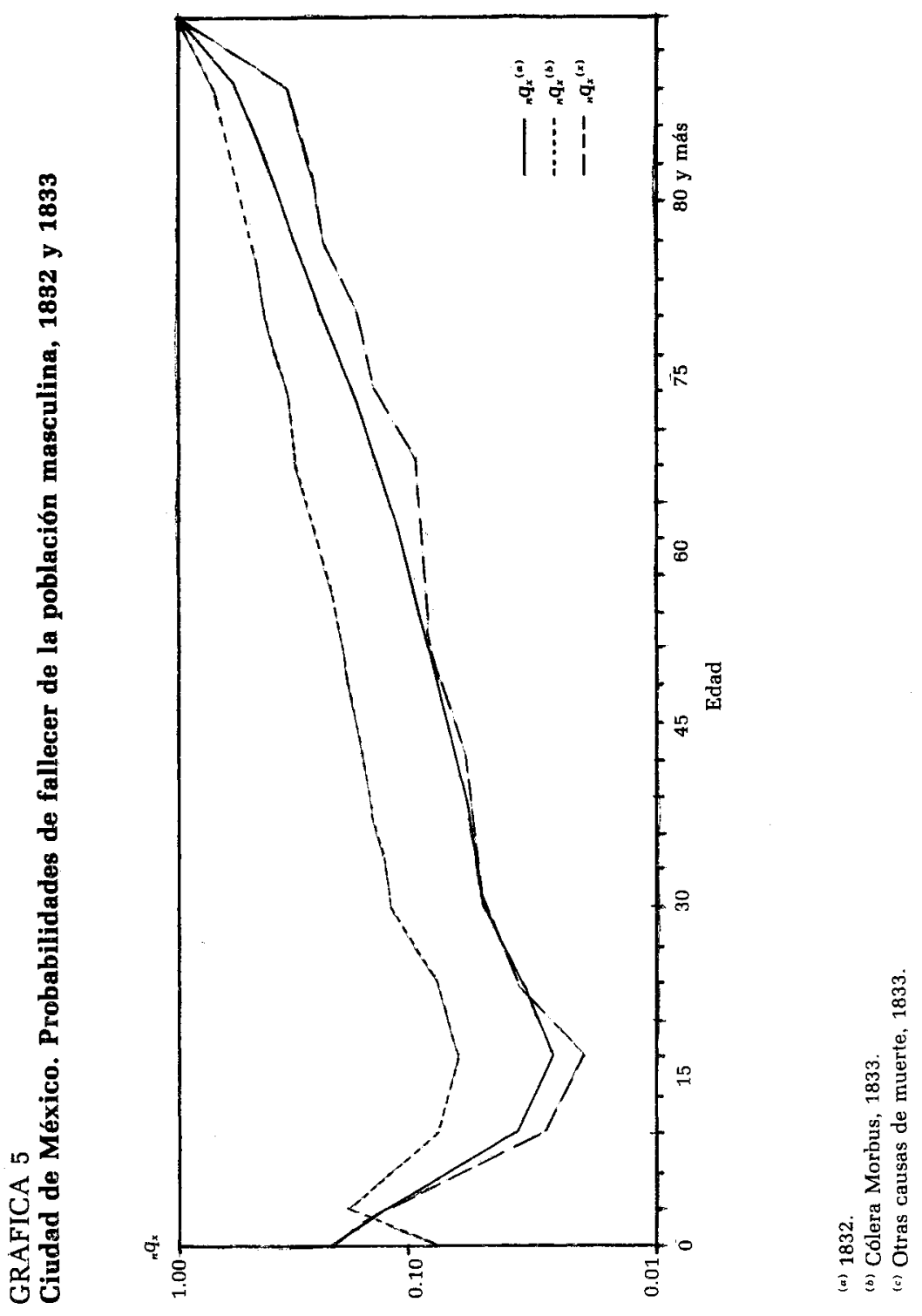




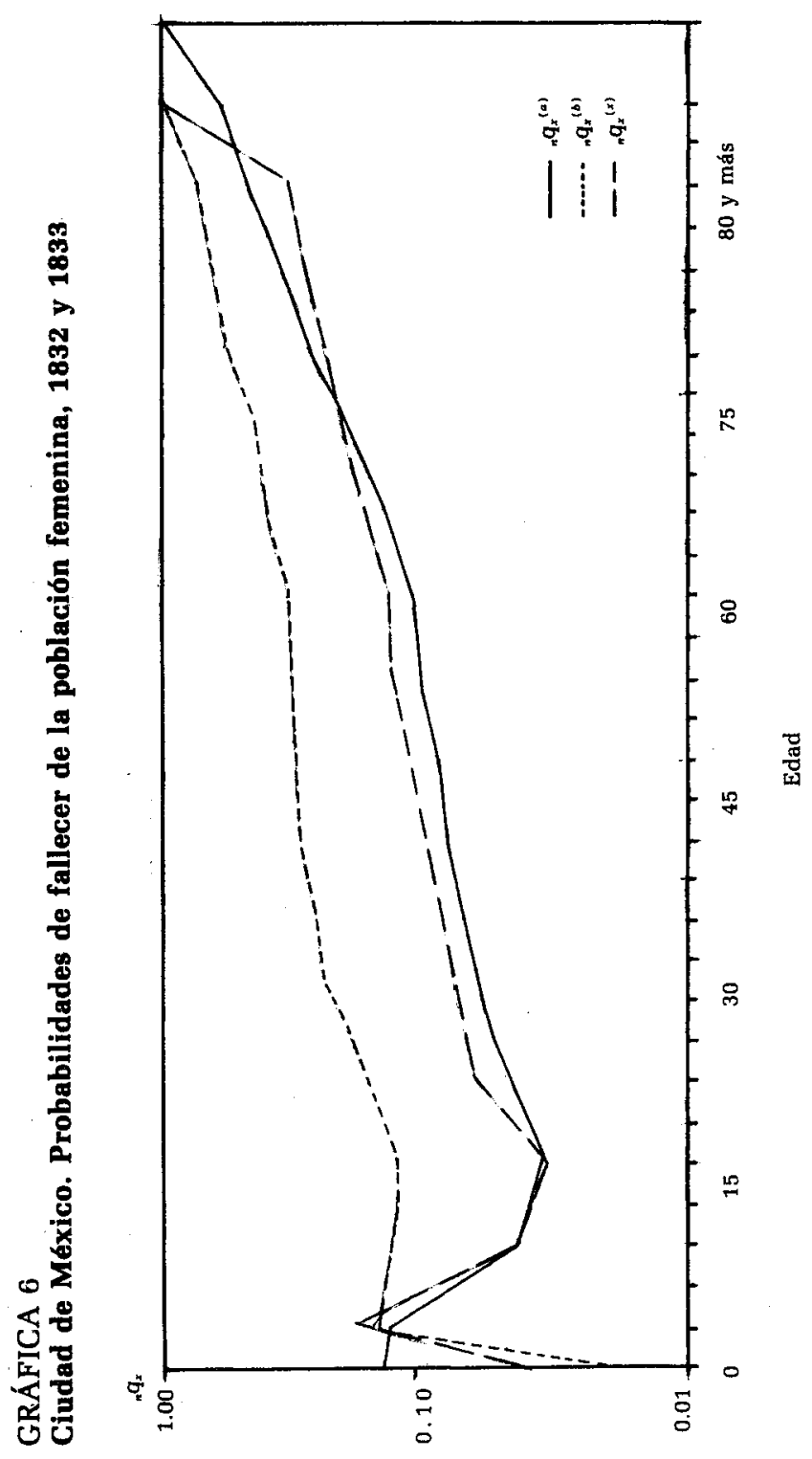

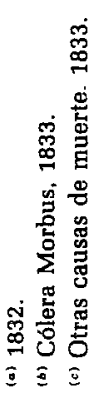




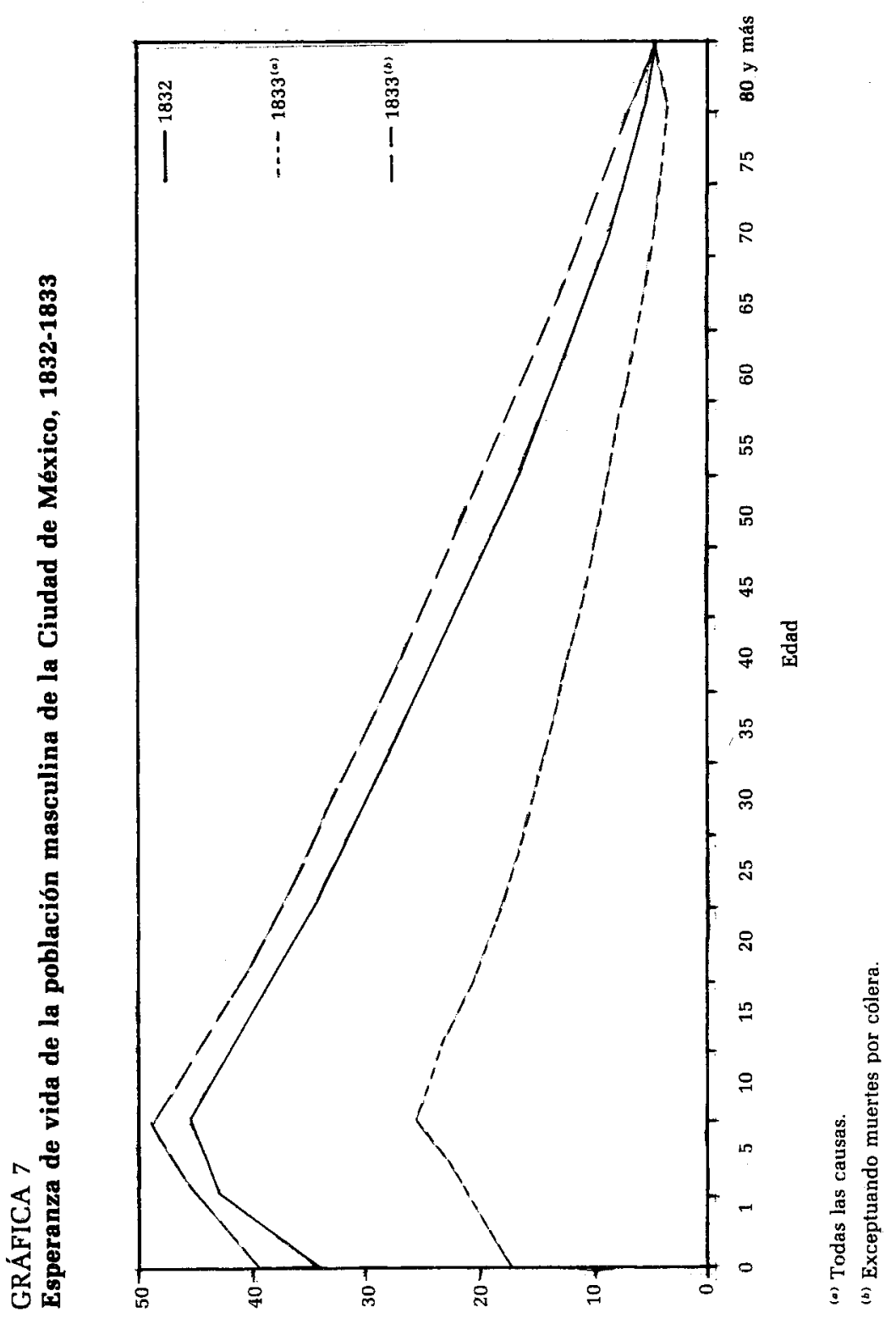




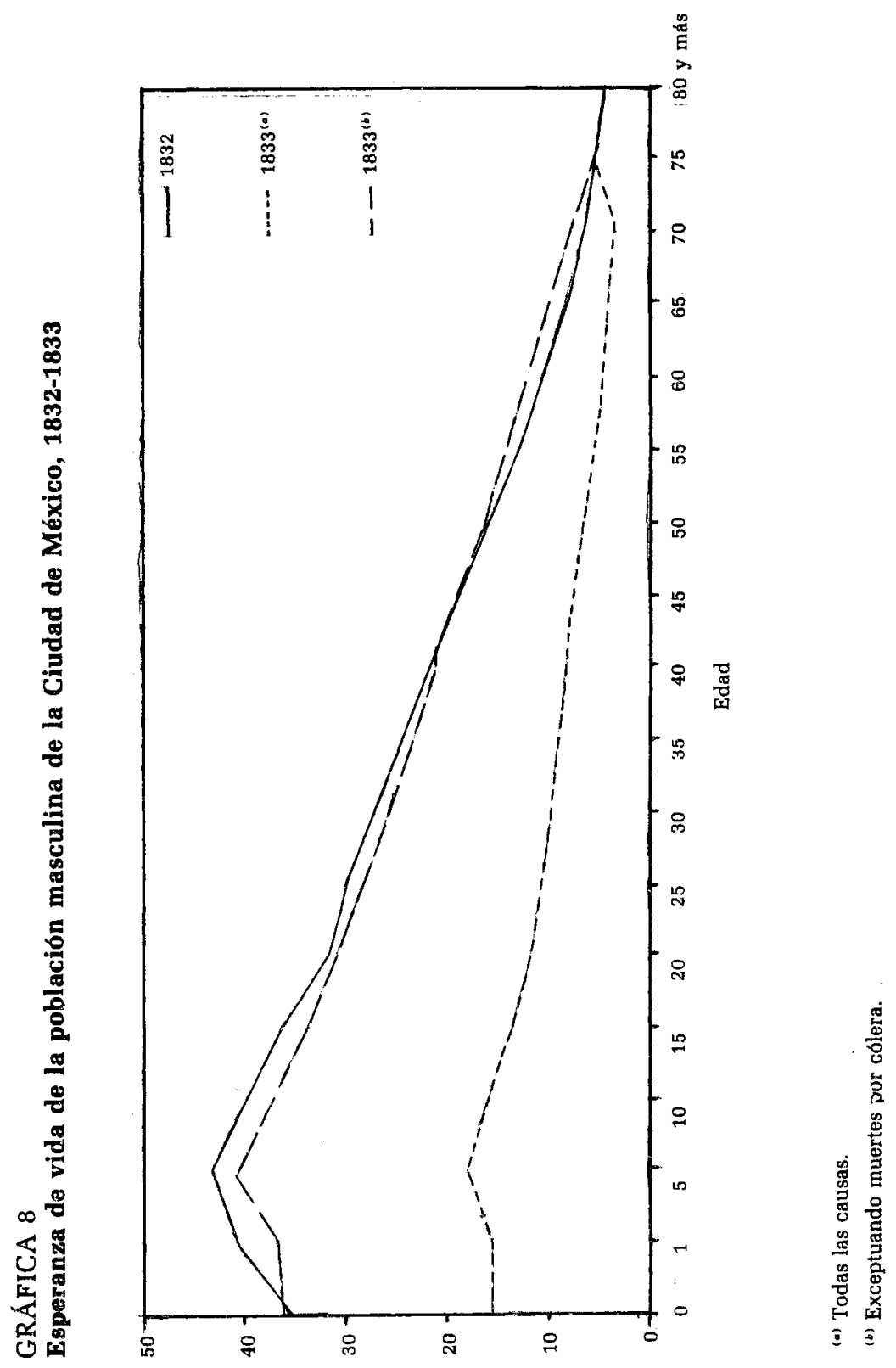




\section{Resultados más sobresalientes y consideraciones finales}

Para comprender el peso específico que tuvo la epidemia de cólera sobre el nivel de la mortalidad, conviene revisar algunos datos acerca de lo ocurrido en 1833 y sobre lo que hubiera sucedido de no haberse presentado la epidemia de cólera, es decir, si se hubieran mantenido los niveles de mortalidad prevalecientes en 1832.

Si comparamos las probabilidades de fallecer, habiendo eliminado las defunciones producidas por cólera, se presentan tendencias similares en ambos años, en los dos sexos. Entre los hombres, en general las probabilidades de fallecer en 1832 son mayores que en 1833 (cuando se elimina la epidemia de cólera), a excepción de la edad 15 , en donde la relación es la inversa $(37 \%$ en 1832 y $40 \%$ en 1833).

Aunque no disponemos de evidencia empírica que apoye esta hipótesis, podría decirse que las probabilidades de fallecer entre uno y otro año debieran ser más parecidas entre ambas fechas de lo que realmente son, lo que da pie para afirmar que muchas de las defunciones cuya causa registrada fue el cólera en realidad pudieron ser ocasionadas por otras enfermedades. En este sentido, algunos de los decesos que en épocas normales hubieran sido clasificados bajo rubros como "estómago", "diarrea", "infección intestinal", "vómitos", etc., al suceder en etapa de epidemia fueron clasificados como si hubieran sido provocados por el cólera.

En algunas edades las diferencias son notorias: a la edad 50, por ejemplo, la probabilidad de fallecer observada es de $147 \%$ en 1832 y de $101 \%$ en 1833 (46 defunciones menos); en la edad 75, de $564 \%$ en 1832 y de $347 \%$ en 1833 (217 decesos de diferencia), etcétera.

Las probabilidades de fallecer en uno y otro año se entrecruzan en el caso del sexo femenino, de manera que cualquiera de los dos años estudiados presenta cifras más altas, dependiendo de la edad. Las diferencias son menores que las observadas entre los hombres, pero hay que destacar el hecho de que la ${ }_{1} \mathrm{q}_{0}$ es sustancialmente menor en 1833: 38 frente a 145\%, lo que arroja una diferencia de 107 defunciones por cada mil nacidas vivas, situación peco probable de darse en la realidad.

Por lo que respecta a las esperanzas de vida, en el caso de los hombres ésta siempre es mayor en 1833 respecto ai año anterior, a excepción del último grupo de edades. La mayor diferencia se observa en la $\mathbf{e}_{0}$ (5.21 años); desde la edad uno, la diferencia de dos años inicia el ascenso para alcanzar un máximo de 3.43 años en la edad 45 y volver a descender.

En el caso del sexo femenino, la esperanza de vidá resulta más 
elevada en uno y otro año, indistintamente, dependiendo de la edad. La $e_{0}$ es mayor en 1833 por 0.6 años; desde la edad uno hasta la 35 es mayor la expectativa de vida de 1832 (con diferencias que van desde 3.97 hasta 0.59 años), pero la relación se invierte nuevamente en los últimos grupos de edades.

Las diferencias de las probabilidades de fallecer se manifiestan no sólo en diferencias en la esperanza de vida, sino que se traducen también en el número de sobrevivientes de cada grupo de edades considerado. Entre los hombres, la cantidad de sobrevivientes siempre es mayor en 1833 en cualquier grupo de edades, y las diferencias van desde 8140 (edad 1 a 4) hasta 5199 (edad 45 a 49). Las mujeres, por su parte, muestran una tendencia diferente: en los primeros grupos de edades y hasta el 30-34, inclusive, hay mayor cantidad de sobrevivientes en 1833, resultado de una mortalidad más baja, pero a partir del grupo 35-39 la relación se invierte, para volver a cambiar en el grupo de 70 a 74 años de edad.

La epidemia de cólera deja sentir su impacto no sólo en las probabilidades de muerte observadas, las esperanzas de vida estimadas y los sobrevivientes esperados en cada grupo de edades, sino que afecta también a la estructura por edades de la población. Si se elaboran pirámides de edades para 1833, en las que se establezca la diferencia en la estructura cuando se consideran todas

\section{GRÁFICA 9}

\section{Ciudad de México, 1833. Población estimada después de la epidemia} de cólera

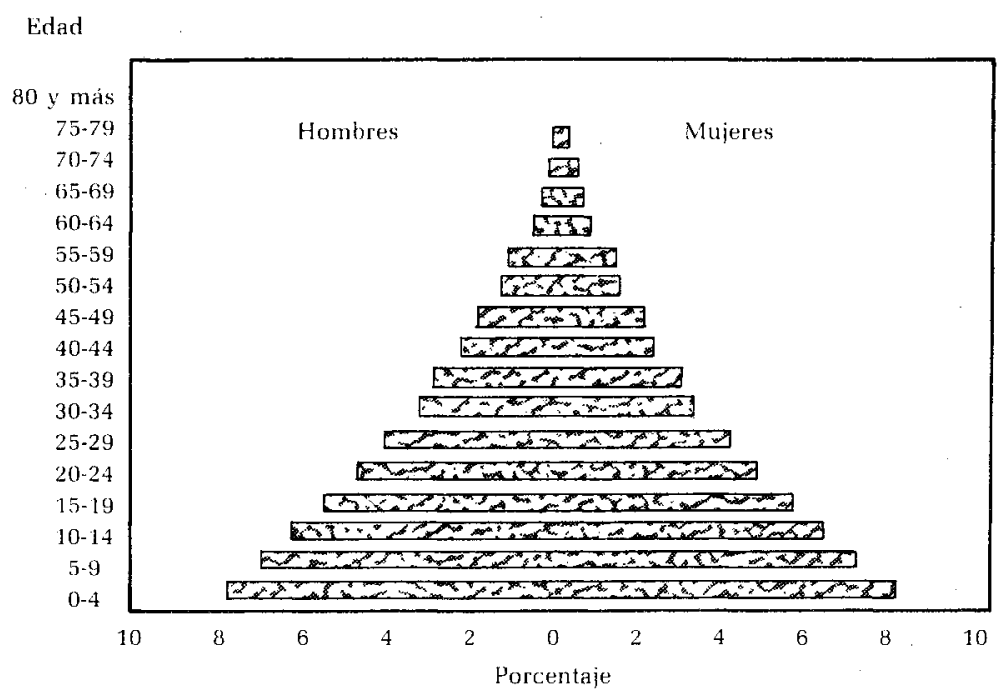


blezca la diferencia en la estructura cuando se consideran todas las defunciones y cuando se descartan las que fueron producidas por el cólera morbus, se observa que hay algunos traslados de proporciones entre grupos de edades.

La pirámide (que no considera el efecto de la migración) presenta una ligera disminución en su base, en ambos sexos, una ampliación (también ligera) de los grupos siguientes (hasta el 25-29) y relaciones variadas en los grupos de edades posteriores, dependiendo del sexo. Aunque aparentemente las diferencias no son significativas, para llegar a conclusiones más acertadas y más apegadas a la realidad es necesario tomar en cuenta diferentes aspectos.

Un primer elemento que debe considerarse es el que se relaciona con la estructura inicial de la población, la que ha sido estimada suponiendo estabilidad, condición que difícilmente se cumple en circunstancias como las que atravesaba la Ciudad de México durante el siglo XIX. Las constantes epidemias, la guerra de Independencia, la inestabilidad política y otros factores hacen poner en duda tal "estabilidad" por lo que a mortalidad se refiere. Si además consideramos que México constituía (y sigue constituyendo) el centro económico, político y administrativo más importante del país, difícilmente la podríamos concebir como "cerrada" a la migración. Lo más probable es que la población no fuera estable y que no presentara tal regularidad en su distribución por sexo y edad.

El otro aspecto que resulta importante resaltar es el que se relaciona con los efectos posteriores de la epidemia y de la mortalidad en ciertos grupos de edades. Casi $5 \%$ de la población total murió a consecuencia del cólera, y aunque puede parecer que se trata de un porcentaje poco elevado, las pérdidas tuvieron consecuencias demográficas para las generaciones siguientes. Los 1200 niños (hombres y mujeres) de 0 a 4 años de edad que fallecieron como resultado del cólera dejaron generaciones incompletas a largo plazo (15 o 20 años): resulta factible que la disminución en la base de la pirámide se tradujera en un decremento en el número total de nacimientos en años posteriores.

En adición, el deceso de 2659 individuos entre 15 y 44 años afectó a hombres y mujeres en edad reproductiva; su desaparición evitó la exposición al riesgo de concebir de madres de distintas edades y la natalidad y la nupcialidad disminuyeron a corto plazo. De hecho, la epidemia debe haber tenido, entre otros efectos, el de retardar algunos nacimientos (cambio en el calendario), el de provocar abortos y decesos entre recién nacidos (que no aparecen registrados como bautismos ni como decesos), y defunciones de mu- 
jeres encinta que hubieran dado a luz y elevado el número total de nacimientos.

Las consecuencias que para la población de la Ciudad de México trajo consigo la epidemia de cólera de 1833 no son fácilmente cuantificables y resulta necesario llevar a cabo estudios más detallados que permitan descubrir el papel que ésta y las demás epidemias jugaron en el desarrollo de la población mexicana del siglo XIX y de etapas históricas anteriores.

Sabemos que entre los años 1793 y 1820 la Ciudad de México incrementó su población en aproximadamente $37 \%$ y que, a partir de entonces, entró en un periodo de crecimiento poblacional lento, llegando incluso a ser negativo en periodos de crisis como el de la epidemia de cólera. Pasados los periodos de guerra o de epidemias, la mortalidad retrocede a los niveles considerados "normales", entrando en etapas de relativa estabilidad. Sin embargo, la población se recupera poco, y quienes contribuyen a esa recuperación son, fundamentalmente, los migrantes que vienen a refugiarse en la urbe, huyendo de críticas situaciones económicas o de los conflictos de desajuste político.

Sabemos también que la epidemia de cólera afectó a todos los sectores sociales, sin distinción de sexo y edad, pero su impacto debe haber sido diferencial por barrios y, seguramente, por clases sociales y/o grupos étnicos. Al respecto, Ruiz y Sandoval escribía en 1833 "que (la enfermedad) prefería a las personas de malas condiciones higiénicas, por lo cual hizo en los indígenas tantos perjuicios" (Ruiz y Sandoval, 1883). Si las defunciones se analizan por parroquia, podemos observar que los barrios más afectados fueron los situados al noreste de la ciudad, en los que se manifestó por primera vez (la epidemia hizo su entrada inicialmente por Tampico). En estas zonas se dejaron sentir sus efectos devastadores antes de que comenzaran a tomarse las primeras medidas higiénicas para combatirla.

Las condiciones sanitarias entre las distintas zonas de la ciudad eran diferentes: por una parte, las fuentes analizadas indican que los basureros se encontraban en los extremos de la ciudad y que éstos constituían verdaderos focos de infección para los barrios aledaños; por la otra, los españoles e indígenas se encontraban ubicados (en la mayoría de los casos) en zonas diferentes, contando con infraestructura urbana también diferencial. Los barrios del centro de la ciudad estaban ocupados por una mayoría blanca, en tanto que los indígenas residían, en su mayor parte, en los barrios más alejados y con menor cantidad de servicios.

A partir del mes de julio en que fueron consignados los primeros casos de cólera, las muertes aumentaban diariamente a pesar 
de las medidas sanitarias instrumentadas por el gobierno: el Consejo Superior de Salubridad impulsó la atención y la vigilancia, y acordó socorrer con más prontitud a las personas afectadas; posteriormente inició la publicación de boletines en los que se consignaban los métodos curativos y preventivos más "modernos" y "eficaces", e instrumentó mecanismos para difundir las reglas y medidas de higiene que debía observar la población para evitar el contagio; se instalaron lazaretos y hospitales por diversos rumbos, apoyados por el trabajo de las Hermanas de la Caridad, se tomaron medidas restrictivas concernientes a la circulación de las personas, se impidió la venta de licores y de otros productos, se abrieron boticas especiales que facilitaran las recetas a la mayor brevedad posible y con el cuidado requerido en estos casos, se establecieron depósitos especiales para los cadáveres en espera de sepultura y se suspendió el entierro de difuntos dentro de las iglesias.

Éstas y otras medidas trajeron consigo cambios importantes en la organización social de la ciudad y sus efectos se dejaron sentir también en el ámbito de la economía: se prohibió la introducción de algunos productos considerados transmisores del virus (carne, verduras, bebidas), se impidió la venta de los mismos y se suspendió la actividad de algunos establecimientos de almidonería, curtiduría y tocinería; estas medidas contribuyeron a que se acrecentara el desempleo abierto y a que escasearan muchos de los productos de primera necesidad, aumentando los precios en forma desorbitada.

Si tomamos en cuenta, además, que $43 \%$ de los fallecidos por causa del cólera tenían entre 15 y 44 años de edad, es decir, se encontraban en edad reproductiva, es fácil suponer que la ausencia de esta población trajo consigo consecuencias económicas de gran envergadura.

La organización urbana también sufrió modificaciones. Si consideramos que el aspecto físico de una ciudad es el resultado de las fuerzas entre una población que necesita un espacio determinado para desarrollar sus actividades y un medio físico con características específicas que condicionan las posibilidades de satisfacer esas necesidades de espacio, y tomando en cuenta las diferentes políticas y medidas económicas instrumentadas por los grupos en el poder y las relaciones sociales de la ciudad con su entorno, es fácil suponer que el impacto que tiene sobre la ciudad una crisis de esta naturaleza es considerable.

Existen una gran cantidad de factores que se influyen y se modifican entre sí y cuya interacción promueve el desarrollo urbano; por una parte se encuentran los factores que caracterizan a la po- 
blación y determinan su estructura socioeconómica; ${ }^{13}$ por la otra, se ubican aquellos factores concernientes a la estructura física de la ciudad ${ }^{14}$ todos ellos conjugando su acción para ofrecer una determinada capacidad de espacio y comunicación, y condicionando las posibilidades de localización de la población.

En este marco, las transformaciones sufridas por la estructura de la población y por los hechos demográficos influyeron de manera determinante en la configuración urbana. A partir de la epidemia de cólera de 1833 comenzaron a implementarse medidas sanitarias (introducción de drenaje, alcantarillado y agua potable, construcción de cañerías e instrumentación de un sistema de recolección de los excrementos que se arrojaban en las acequias, etcétera), pero con diferencias, es decir, prepoderantemente en aquellos barrios en los que los habitantes contaban con medios económicos suficientes para subsidiarlos. El resultado previsible fue una diferenciación social más clara y más marcada. Se hacen evidentes las disparidades económicas entre barrios y se manifiesta una mortalidad más elevada entre los más desprotegidos desde el punto de vista socioeconómico. La epidemia de cólera de 1833, aunque no fue la única de esta naturaleza, ${ }^{15}$ dejó sentir su impacto en todos los ámbitos de la vida social, económica y política de la Ciudad de México. En lo que respecta específicamente a la población, las cifras anotadas y los análisis realizados nos muestran su importancia y solamente en lo que se refiere a su crecimiento, se hacen evidentes sus efectos.

A pesar de todo lo que sabemos al respecto, es aún más lo que nos queda por conocer de esta epidemia y de otras que asolaron a la población nacional en el siglo XIX.

\section{Bibliografía}

Aceves Parra et al. (1975), "Enfermedades infecciosas y parasitarias", en Praxis Médica, vol. VI, México, Ediciones Técnicas.

${ }^{13}$ Distribución de la población por sexo y edad, niveles y tendencias de los factores demográficos, clases sociales, tecnología, estructura familiar, tipo de actividad económica que desarrollan y que requieren de un espacio físico, etcétera.

${ }^{14}$ Características naturales del territorio, vias de comunicación y transporte, agua potable, drenaje, disposición de edificios y espacios abiertos, etcétera.

15 Durante el año de 1850 se presentó otra epidemia de cólera morbus de gran magnitud. Los muertos por esta causa oscilan entre 7600 y 9169 , según la fuente a la que se recurra. La epidemia de cólera de 1833 trajo consigo un total de 6165 decesos por esta causa, lo que representa aproximadamente $75 \%$ de los ocurridos en 1850, año en que la población de la ciudad era considerablemente mayor. 
Bustamante, Miguel E. (1982), “La situación epidemiológica de México en el siglo XIX”, en E. Florescano y E. Malvido, Ensayos sobre las epidemias en México, México, IMSS (2 volúmenes).

Cook, S. y W. Borah (1980), Ensayos sobre Historia de la Población: México y el Caribe, México, Siglo XXI Editores (2 volúmenes).

Domínguez, Silverio et al. (1889), El médico práctico doméstico, México, World Publishing Coy, Canadá y Griffin y Campbell México Editores.

García Cubas, Antonio (1870), Apuntes relativos a la población de la República Mexicana, México.

Humboldt, Alejandro de (1970), Tablas geográfico-políticas del Reinò de Nueva España que manifiestan la superficie, población, agricultura, fábricas, comercio, minas y fuerza militar, México, diciembre de 1808. Reproducido en edición de homenaje, México, Secretaría de Programación y Presupuesto, DGE.

Lozano, José María (1892), Sinopsis del cólera, México, Monterrey, Nuevo León.

Maldonado, Celia (1976), Estadísticas vitales de la Ciudad de México: siglo XIX, México, Instituto Nacional de Antropología e Historia, Departamento de Investigaciones Históricas, Seminario de Historia Urbana (Colección científica. Fuentes, Historia Social, 31).

Navarro y Noriega, F. (1969), "Memoria sobre la población de Nueva España”, en Boletín Sociedad Mexicana de Geografía y Estadística, vol. 1. (Reimpreso del artículo original publicado en 1920.)

Passmore, R. y J.S. Robson (1975), Tratado de Enseñanza Integral de la Medicina, Barcelona, Editorial Científico-Médica (4 volúmenes).

Pérez Astorga, Javier (1982), “Tablas de mortalidad por causas en México, 1960-1970", en Revista de Estadística y Geografía, vol. 2, núm. 7, México, SPP.

Reyes, Agustín (1880), Informe que la Comisión Estadística rinde al Consejo Superior de Saiubridad acerca de su trabajo durante el año de 1879, México, Consejo de Salubridad.

Ruiz y Sandoval, Gustavo (1883), "La enfermedad coleriforme en Chiapas”, en Gaceta Médica de México, tomo xvıI, núm. 8, abril de 1883.

SPP (1977), Primer Censo de Población de la Nueva España, 1790. Censo de Revillagigedo "un censo condenado", México, SPP, DGE.

Velasco M.L., Pilar (1984), "La población de la Ciudad de México en el siglo XIX y la mortalidad por cólera en 1833”, tesis para optar por el grado de maestría en demografía, México, El Colegio de México.

(1987), Las políticas sanitarias y las políticas de población en México durante el siglo XIX, México, UNAM, Aportes de Investigación, núm. 16, Centro Regional de Investigaciones Multidisciplinarias.

Velasco, Ildefonso (1880), "Informe que rinde a la Secretaría de Gobernación el Presidente del Consejo Superior de Salubridad del Distrito Federal. . .", en Boletín Consejo Superior de Salubridad I, México, Imprenta del Gobierno, en Palacio, a cargo de A. Sabás y Munguía. 
Anexo

CUADRO A-1

Algunas estimaciones de población, Ciudad de México 1803-1895

\begin{tabular}{|c|c|c|}
\hline Año & Población & Autor \\
\hline 1803 & 137000 & Wibel y de la Cruz, Orozco y Berra, Humboldt \\
\hline 1804 & 137000 & Orozco y Berra \\
\hline \multirow[t]{2}{*}{1805} & 128218 & Tribunal del Consulado \\
\hline & 130000 & Orozco y Berra \\
\hline 1808 & 130000 & Humboldt \\
\hline \multirow[t]{2}{*}{1810} & 180000 & Wibel y de la Cruz \\
\hline & 131026 & García Cubas \\
\hline 1811 & 168846 & Padrón del Juzgado de Policía, García Cubas, Orozco y Berra \\
\hline 1813 & 123907 & Orozco y Berra, Ayuntamiento \\
\hline 1820 & 179830 & Navarro y Noriega \\
\hline 1823 & 165000 & Wibel y de la Cruz \\
\hline 1824 & 155000 & Poinsett \\
\hline 1830 & 151986 & García Cubas \\
\hline 1831 & 250000 & Antonio de Valdez \\
\hline 1833 & 170000 & Orozco y Berra \\
\hline 1838 & 205430 & $\begin{array}{l}\text { Orozco y Berra, Sociedad de Geografía y Estadistica, Junta } \\
\text { Menor del Instituto Nacional de Geografia y Estadistica de } \\
\text { la República Mexicana }\end{array}$ \\
\hline 1842 & 200000 & Mayer \\
\hline 1846 & 200000 & Farnham \\
\hline 1850 & 176306 & García Cubas \\
\hline \multirow[t]{2}{*}{1852} & 170000 & Boyer, Almonte \\
\hline & 200000 & Orozco y Berra \\
\hline 1855 & 200000 & Wibel y de la Cruz \\
\hline 1856 & 185000 & Lerdo de Tejada \\
\hline \multirow[t]{2}{*}{1857} & 200000 & García Cubas \\
\hline & 185000 & Hermosa \\
\hline \multirow[t]{3}{*}{1862} & 200000 & Carcía Cubas \\
\hline & 210000 & Wibel y de la Cruz \\
\hline & 210327 & Pérez Hernández \\
\hline 1865 & 200000 & Guillemin Tarayre \\
\hline 1869 & 230000 & Boyer, García Cubas \\
\hline \multirow[t]{2}{*}{1870} & 240000 & García Cubas \\
\hline & 315906 & I. Vázquez Valle \\
\hline 1874 & 200000 & Geiger \\
\hline 1877 & 230000 & Wibel y de la Cruz \\
\hline 1878 & 205000 & Bates \\
\hline 1880 & 250000 & Winsburgh \\
\hline 1882 & 338000 & Zaremba \\
\hline 1884 & 300000 & García Cubas, Raimond's Vacation Excursions \\
\hline 1890 & 326913 & Ministerio de Fomento (censo) \\
\hline \multirow[t]{3}{*}{1895} & 329774 & Peñafiel \\
\hline & 339935 & Matías Romero \\
\hline & 476413 & Ministerio de Fomento \\
\hline
\end{tabular}


CUADRO A-2

Nacimientos y defunciones registrados en las parroquias de la Ciudad de México, 1800-1860. Años seleccionados

\begin{tabular}{|c|c|c|c|}
\hline Año & Nacimientos & Defunciones & Saido \\
\hline 1800 & 4408 & 2936 & 1472 \\
\hline 1801 & 4556 & 4701 & 485 \\
\hline 1802 & 4820 & 4101 & 719 \\
\hline 1803 & 4703 & 4241 & 462 \\
\hline 1804 & 4645 & 6062 & -1.417 \\
\hline 1805 & 5013 & 5485 & -472 \\
\hline 1806 & 4817 & 4542 & 275 \\
\hline 1807 & 4922 & 4339 & 583 \\
\hline 1810 & 5292 & 5611 & -319 \\
\hline 1811 & 4977 & 5025 & -48 \\
\hline 1812 & 4660 & 6406 & -1716 \\
\hline 1813 & 3207 & 17267 & -14060 \\
\hline 1814 & 4272 & 4365 & -93 \\
\hline 1815 & 4726 & 2968 & 1758 \\
\hline 1820 & 4260 & 3401 & 859 \\
\hline 1824 & 5102 & 5502 & -400 \\
\hline 1825 & 5614 & 9268 & -3654 \\
\hline 1826 & 6720 & 4709 & 2011 \\
\hline 1830 & 5572 & 7826 & -2254 \\
\hline 1831 & 6331 & 4265 & 2066 \\
\hline 1832 & 6072 & 3700 & 2372 \\
\hline 1833 & 5825 & 9445 & -3620 \\
\hline 1834 & 5717 & 4175 & 1542 \\
\hline 1838 & 5751 & 6443 & -692 \\
\hline 1839 & 5915 & 5603 & 312 \\
\hline 1844 & 7029 & 4718 & 2311 \\
\hline 1848 & 6075 & 5300 & 775 \\
\hline 1849 & 7683 & 4022 & 3661 \\
\hline 1850 & 7133 & 10072 & -2939 \\
\hline 1855 & 6348 & 6639 & -291 \\
\hline 1860 & 8026 & 6081 & 1945 \\
\hline
\end{tabular}

Fuente: elaborado con base en la información de Celia Maldonado (1976), Estadísticas vitales de la Ciudad de México: siglo XIX, México, INAH, Colección científica, núm. 31. 
GRÁFICA A-1

Distribución de las defunciones generales, según parroquia, 1833

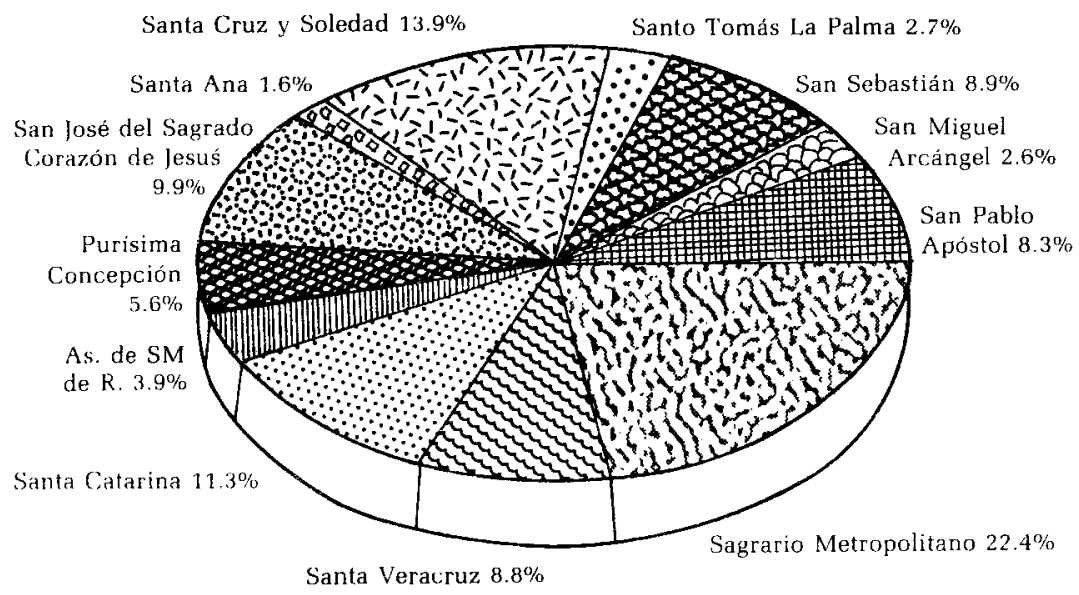

GRÁFICA A-2

Distribución de las defunciones por cólera según parroquia, 1833

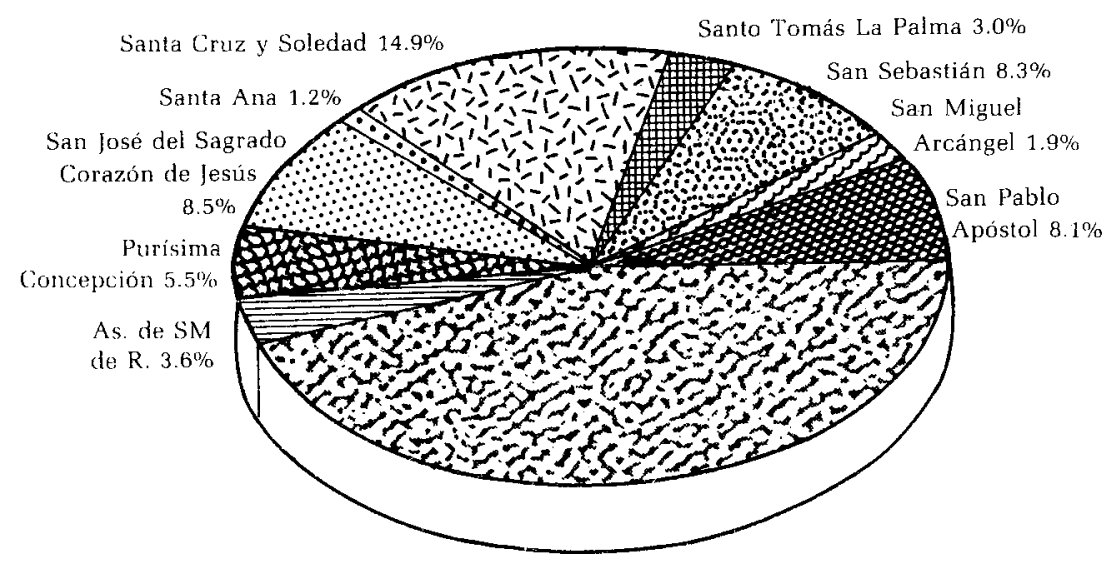

Otras* $44.8 \%$

* Sagrario Metropolitano, Santa Veracruz y Santa Catarina. 
Causas de muerte registradas en las parroquias de la Ciudad de México, 1832 y 1833*

Grupo I: Enfermedades infecciosas y parasitarias, gripe, neumonía, bronquitis $y$ otras enfermedades del aparato respiratorio

- Decentería.

- Estómago.

- Dearrea.

- Ética (parásitos intestinales). Se trata de un vocablo aún usado en las zonas rurales.

- Dolor de estómago.

- Deposiciones.

- Cólera morbus.

- Miserere (se trata, aparentemente, de una gastritis de tipo coleriforme).

- Empacho (vocablo empleado frecuentemente para referirse a la indigestión y a otros trastornos intestinales).

- Cólico.

- Tiricia (ictericia) (nombre común para enfermedades que provocan tono amarillento en la piel y que corresponden, generalmente. a algunas afecciones hepáticas).

- Dicipela (ericipela).

- Sarampión.

- Inflamación de estómago o vientre.

- Escarlatina.

- Basca (náusea).

- Granos luna irritación cutánea de esta naturaleza puede responder a intoxicaciones o a infecciones de la piel; en cualquier caso, se trata de una manifestación de padecimientos infecciosos).

- Fríos (paludismo).

- Derrame de leche (así se les llama, aún en la actualidad, a algunas diarreas de los lactantes).

- Del pecho.

- Tos.

- Pulmonía.

- Sofocación (dipnea o dificultad para respirar).

- Pulmón.

- Tubérculo (tuberculosis).

- Garganta (difteria).

- Alferecía (aunque los diccionarios consideran ésta como una forma de epilepsia infantil, los testimonios orales de ancianos y la cantidad de defunciones de adultos por esta causa indican que puede tratarse de pulmonía).

- Anginas.

- Tisis (tuberculosis).

* Se respetó la ortografía original. 
Grupo II: Lesiones que afectan al sistema nervioso central, fiebre reumática, enfermedades del corazón, enfermedades arterioescleróticas y otras degenerativas; en general, las enfermedades del aparato circulatorio y las denominadas enfermedades cardiovasculares y renales

- Úlcera.

- Hidropecía.

- Llaga en la cadera (no parece corriente el hecho de que una llaga en la cadera se convierta en causa de defunción; más bien parece que se tratara de irritaciones provocadas por una estancia prolongada en el lecho, debido a otro tipo de enfermedades, posiblemente degenerativas.)

- Reumatismo.

- Escorbuto (avitaminosis).

- Apoplejía.

- Angina de pecho.

Grupo III: Cáncer y neoplasmas malignos

- Tumor.

- Cáncer.

- Pólipo (tumor).

- Cangro (cáncer).

Grupo IV: Accidentes, suicidios, homicidios y traumatismos. Muertes violentas en general

- Insulto (éste es uno de los nombres que se daban a la congestión ocasionada por el exceso de eịercicio después de ingerir alimentos; sin embargo, el vocablo también fue empleado para describir infartos y síncopes cardiacos. En este caso, y debido a una gran cantidad de defunciones de infantes provocadas por esta causa, hemos decidido emplearlo según la primera de las acepciones mencionadas).

- Golpe de vaca.

- Golpes.

- Pedradas.

- Heridas.

- De pleito.

Grupo V: Comprende todas las enfermedades no incluidas en los capítulos anteriores y, en general, todas las causas mal definidas

- Parto.

- Inflamación.

- Dolor de costado (¿pulmonía? ¿absceso hepático?).

- Fiebre. 
- Vejez.

- Dolor.

- Hígado (¿cirrosis? ¿hepatitis?).

- Hambre.

- Cruda (¿congestión alcohólica? ¿síndrome de abstinencia? ¿delirium tremens?).

- Irritación (¿infección?).

- Al nacer.

- Hipocondría.

- De repente (iinfarto?).

- Complicación.

- Punzadas en la cabeza (¿tumor?).

- Debilidad nerviosa.

- Opresión de orina (¿cálculos?).

- De una pierna (¿gangrena?).

- Derrame de bilis.

- Llaga en útero.

- Sobreparto (¿fiebres puerperales?).

- Apostema (también descrito como postema, es un vocablo empleado para definir algunos padecimientos que provocan vómitos de pus).

- Salica.

- Debilidad.

- Encordio (absceso en la ingle, quizá producto de la inflamación de un ganglio, por lo que podría incluirse entre las enfermedades infecciosas; a falta de precisión decidimos incluirle entre las mal definidas). 
